\title{
Extending the utility of artiodactyl postcrania for species-level identifications using multivariate morphometric analyses
}

\author{
Edward Byrd Davis and Jonathan Jean-Michel Calède
}

\begin{abstract}
Studies of paleoecology are most powerful when relative abundance data are available at fine taxonomic scales and large sample sizes. Postcranial elements are abundant but seldom identified to species, reducing potential sample size. We investigate whether antilocaprid astragali, abundant in the Late Miocene deposits of the Great Basin, can be identified to species, improving sample sizes. Our analysis of African and Asian bovid data from the literature suggests species should be distinguishable using astragalar dimensions. For our case study we use three species of antilocaprids, llingoceros alexandrae, llingoceros schizoceras, and Sphenophalos nevadanus from the Hemphillian ( $\sim 8 \mathrm{Ma}$ ) Thousand Creek Fauna of northwestern Nevada. These species are diagnosed by their horncores, but previous comparisons of their dentition have shown no clear separation between the species. Our analysis of $>200$ antilocaprid astragali from Thousand Creek indicates there is enough variation to tentatively reject the hypothesis of only one species, but the distribution does not allow assignment of individual astragali to species. Combined with horncore morphology, our results suggest differences in male-male competition and a slight difference in body size kept the two genera out of competition while ecological similarity and/or shared ancestry created a continuous distribution of astragalar dimensions. The data cannot resolve whether $I$. alexandrae and $I$. schizoceras are distinct species. Additionally, we explored the range of effectiveness of a published discriminant function developed to derive environmental preference from African bovid astragali. Applying this discriminant function to Antilocapra proved ineffective, likely a consequence of the distinct evolutionary histories of antilocaprids and bovids.
\end{abstract}

Edward Byrd Davis. Department of Geological Sciences and Museum of Natural and Cultural History, University of Oregon, Eugene, Oregon, 97403-1272, USA. edavis@uoregon.edu

Jonathan Jean-Michel Calède. Department of Biology, University of Washington, Seattle, Washington, 98195-1800, USA. caledj@uw.edu

KEY WORDS: discriminant analysis; CV; Antilocapridae; Bovidae; habitat; abundance

PE Article Number: 15.1.1A

Copyright: Society of Vertebrate Paleontology January 2012

Submission: 16 November 2010. Acceptance: 4 July 2011

Davis, Edward Byrd and Calède, Jonathan Jean-Michel. 2012. Extending the utility of artiodactyl postcrania for species-level identifications using multivariate morphometric analyses. Palaeontologia Electronica Vol. 15, Issue 1; 1A:22p; palaeo-electronica.org/content/2012-issue-1-articles/68-artiodactyl-postcrania 


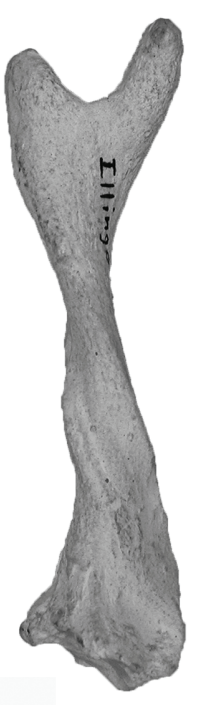

1.1
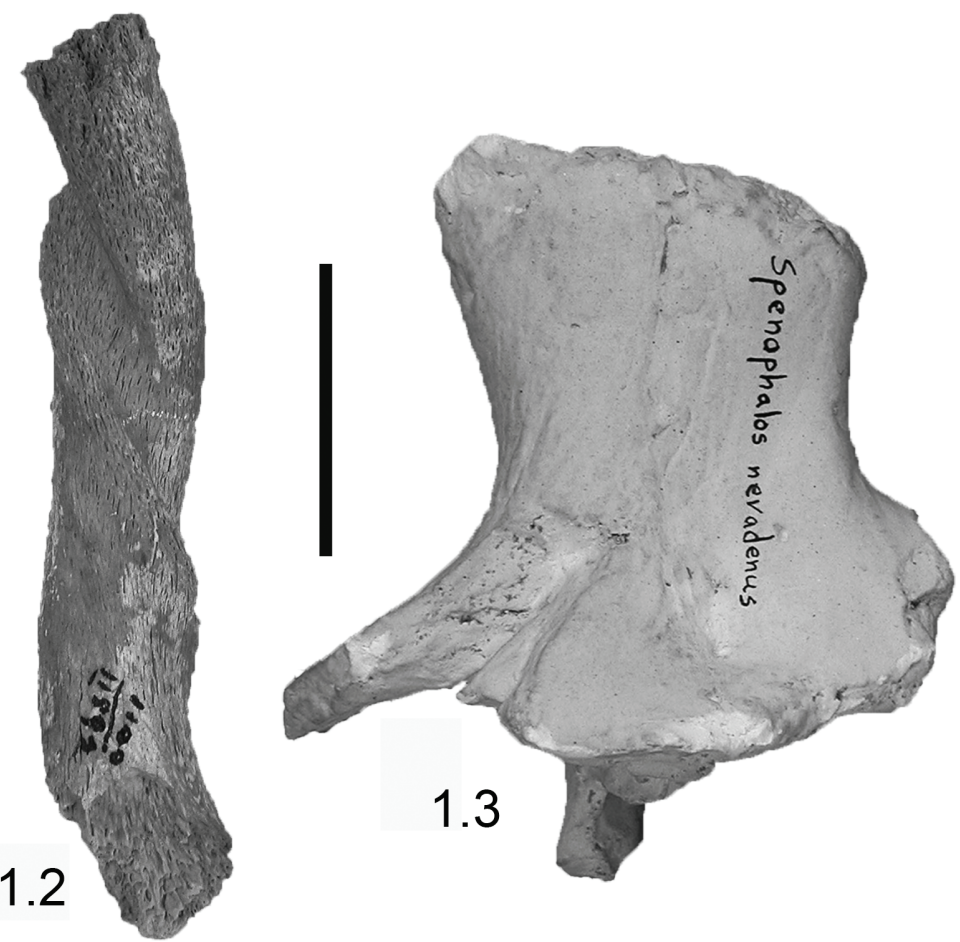

FIGURE 1. Photographs of fossil antilocaprid horns. 1.1, llingoceros schizoceras; 1.2, I. alexandrae; 1.3, Sphenophalos nevadanus.

\section{INTRODUCTION}

Large-scale studies of mammalian diversity and evolution (e.g., Alroy et al., 2000; Barnosky et al., 2005) require large numbers of fine-scale taxonomic identifications; consequently, one of the purposes of new alpha taxonomy in paleontology should be to offer the largest, best supported dataset for future diversity and evolutionary studies. In particular, relative abundance analyses, important for understanding local, regional, or even global scale changes in faunas (Shotwell, 1963; Krause, 1986; Olzewski, 2004; Davis, 2005; Davis and Pyenson, 2007), require large sample sizes for the number of identified specimens (NISP) or the minimum number of individuals ( $\mathrm{MNI}$ ). The rich fossil record of the Great Basin is a critical dataset in the study of mammalian paleoecology in the Cenozoic (Barnosky et al., 2005; Davis, 2005; Kohn and Fremd, 2008), but most mammalian fossil deposits in the Great Basin consist primarily of fragmentary postcranial elements, with rare preservation of skulls (Davis and Pyenson, 2007). The preservation of teeth is enough for fine taxonomic resolution in most mammal groups, but for one group of artiodactyls, the Antilocapridae, taxa are only identified using horncores. Those horncores are extremely rare in Great Basin deposits even though both males and females bear horns within the Antilocaprinae (including Ilingoceros, Sphenophalos, and Texoceros), as opposed to the more basal merycodontine antilocaprids.

Despite their abundance, postcranial elements have seldom been used to identify antilocaprid taxa at the species level; consequently, a large number of fossil remains are ignored when analyzing antilocaprid diversity in the Late Miocene deposits of the Great Basin, a time period critical to understanding both overall faunal response to climate change (Alroy et al., 2000; Barnosky et al., 2005; Kohn and Fremd, 2008; Finarelli and Badgley, 2010) and the decline of antilocaprids to a single extant species (Janis and Manning, 1998; Davis, 2007). We explore whether artiodactyl astragali will allow species-level identification. If so, artiodactyl astragali, commonly preserved in the Late Miocene deposits of the Great Basin, will be able to provide a robust and abundant data source for analyses of Great Basin community paleoecology and evolution, adding substantially to our knowledge of paleoecology. We focus on antilocaprids here, but the method shows some promise for extensions to camelids as well (Breyer, 1983; Davis, 2004). 
As our case study, we use the antilocaprids from the early early Hemphillian (Hh1) Thousand Creek Fauna ( 7-8 Ma, Perkins et al., 1998; Prothero and Davis, 2008) of northwestern Nevada. This fauna contains a diversity and abundance fauna of large mammals, including two genera of antilocaprids (Davis 2007) but no dromomerycids or other ruminants (Merriam, 1911; Frick, 1937; Janis et al., 1998; Carrasco et al., 2005). The species of antilocaprids from Thousand Creek include llingoceros alexandrae Merriam, 1909, Ilingoceros schizoceras Merriam, 1911, and Sphenophalos nevadanus Merriam, 1909 (Figure 1). Merriam and Stock (1928) first suggested a close evolutionary relationship for the genera, and current thinking still supports the two as sisters (Janis and Manning, 1998). Frick (1937) illustrated a large range of variation in horncores of Ilingoceros and proposed that I. schizoceras was a female or juvenile of $I$. alexandrae, but no one has subsequently treated these two species.

Although these three names have become established in the literature, efforts to diagnose the species on the basis of anything but horncores have been futile. Merriam (1911) attributed two large molars to $S$. nevadanus, and several small postcrania to $I$. schizoceras, arguing that $S$. nevadanus horncores belonged to a larger animal than llingoceros. However, Stirton (1932) analyzed all the antilocaprid teeth from Thousand Creek and concluded llingoceros and Sphenophalos were indistinguishable from dentition. Consequently, he argued, the two genera might be too closely related to be distinguished by dental morphology or size, or might represent the male and female of a single species. No postcrania have been found directly associated with horncores at Thousand Creek, preventing definitive species assignment of any specimens except horncores; consequently, NISPs and MNIs are two orders of magnitude lower than their potential.

Fossil remains from other regions have shed some light on Ilingoceros and Sphenophalos relationships. The presence of Sphenophalos without llingoceros in two other sites (Furlong, 1932; Barbour and Schultz, 1941) removes support for the two as sexual dimorphs, but small sample sizes (five and one) decrease the power of this argument. A seasonal bias in preservation might have captured only one sex in one locality, but coincidence in two geographically distant sites (Oregon and Nebraska) seems less likely. There are no records of Ilingoceros outside of Thousand Creek.
Typical of many Great Basin Miocene fossil mammal localities, the Thousand Creek Formation is composed of tuffaceous sedimentary rocks with locally distributed pumice and ash layers (Green, 1984). The mammal fauna is represented mostly by postcrania, with a majority of podial elements, deposited close to the shores of one or more lakes where scavenging occurred before burial (Davis and Pyenson, 2007). Establishing a new way to identify antilocaprid (or other artiodactyl) species from isolated podials would dramatically increase the sample size available for paleoecological analysis from this and other taphonomically similar Great Basin Miocene sites. To that end, we have used multivariate techniques to describe the morphological diversity of antilocaprid astragali from the abundant postcranial remains recovered from Thousand Creek, with the goal of assessing the number of antilocaprid species present in the fauna.

We have grounded our paleobiological analysis in neo-biological data, building upon an investigation of African antelope astragali. The discriminant function analysis (DFA) of DeGusta and Vrba (2003) has shown promise for diagnosing ecological differences from the morphology of artiodactyl astragali. Analyzing eight morphological dimensions of the astragali of bovid antelope, DeGusta and Vrba (2003) were able to discriminate among four habitat preferences with a precision of $67 \%(p<0.0001)$. That significant success for habitat preferences suggested to us the potential for similar success in discriminating species from astragali. If the modern antelope data from DeGusta and Vrba (2003) were to contain enough taxonomic information to allow species-level diagnosis, it should be possible to similarly diagnose the extinct antilocaprid species from Thousand Creek. To test our hypotheses regarding specieslevel diagnosis on the basis of astragalar shape, we performed a new by-species DFA using the data from the by-habitat DFA of DeGusta and Vrba (2003). Additionally, to provide a large baseline for artiodactyl astragalus variation, we compared the coefficients of variation for the species from DeGusta and Vrba (2003) as well as Weinand (2007) to three groups: modern Antilocapra americana, a fossil sample known to be a single species (Texoceros guymonensis from the Optima fauna of Oklahoma), and the unknown sample of antilocaprid astragali from Thousand Creek, Nevada. 

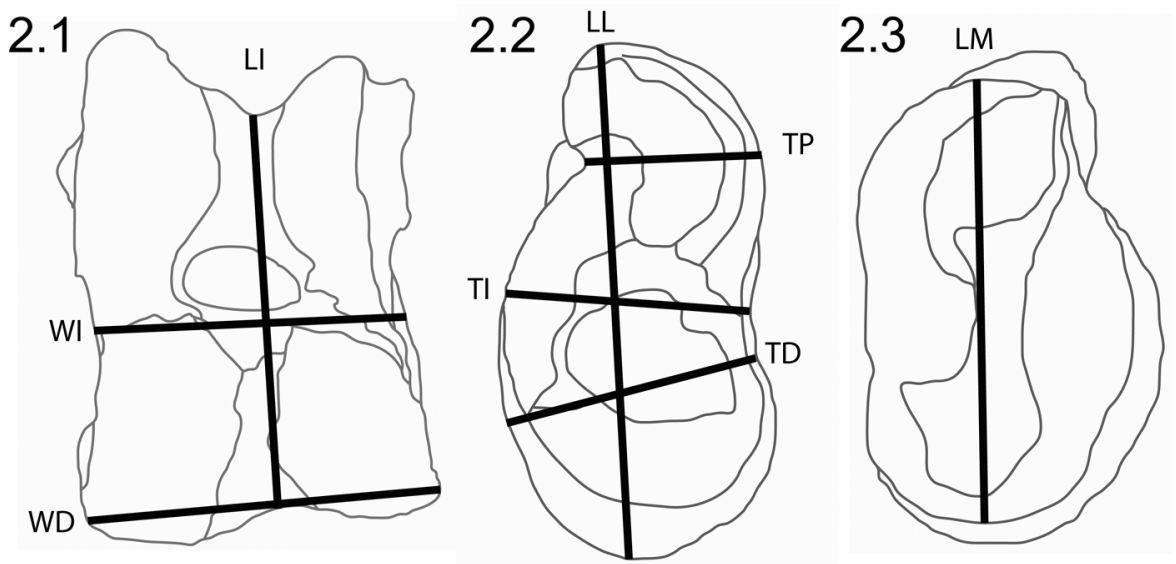

FIGURE 2. Illustration of idealized antilocaprid astragalus, indicating the eight dimensions used in this analysis, following DeGusta and Vrba (2003). 2.1, anterior view; 2.2, lateral View; 2.3, medial view. Abbreviations: LM= medial length; $\mathrm{LI}=$ intermediate length; $\mathrm{LL}=$ lateral length; $\mathrm{TD}=$ distal thickness; $\mathrm{TI}=$ intermediate thickness; $\mathrm{TP}=$ proximal thickness; $W D=$ distal width; $W I=$ intermediate width.

\section{MATERIALS AND METHODS}

\section{Material Examined}

In addition to the bovid data from DeGusta and Vrba (2003) $(n=218)$ and Weinand (2007) $(n=81)$, we analyzed measurements from 26 modern Antilocapra americana and 290 fossil antilocaprid astragali (223 from Thousand Creek and 67 from Optima). Thousand Creek astragali come from the University of California Museum of Paleontology (UCMP) $(n=136)$ and the Los Angeles County Museum (LACM) ( $n=87)$ (Appendix 1). Optima astragali, assigned to Texoceros guymonensis Frick (1937), are included as a control. These specimens, from the Frick Collection of the American Museum of Natural History (F:AMNH), are from the type locality of the species, the Optima local fauna (Frick, 1937; Schultz, 2002) in the Guymon area of Texas County, Oklahoma. The T. guymonensis sample provides a control distribution for a single species of closely related antilocaprid. Modern Antilocapra americana astragali from the collections of the University of California Museum of Vertebrate Zoology (MVZ) provide a single-species control distribution from a closely related modern population. To obtain the largest sample possible, we included specimens from the entire geographic range of the species, making the comparison with the Thousand Creek sample more conservative, because the geographic variation of our sample must have higher variance than a modern single-locality population. Adult astragali cannot be differentiated from juveniles because they fuse early on in an individual's life. As a conse- quence, the specimens of fossil antilocaprids measured might include some juveniles.

\section{Body Mass and Comparisons of Coefficients of Variation}

The coefficient of variation ( $V$, standard deviation divided by the mean) is a unit-free measure of dispersion that has been suggested to allow comparisons among organisms of different sizes (Carrasco, 1998). It should therefore be possible, using coefficients of variation, to compare morphometric measurements of animals with very different body masses. However, when comparing the coefficients of variation of the astragali measurements of modern bovids, it became apparent to us that a positive correlation remains between body mass and coefficient of variation, indicating that the metric does not remove all of the influences of size. The relationship between $V$ and mass is significant for the three measurements of length of the astragalus (LM, LI, and LL) as well as one of the measurements of height $(\mathrm{TI})$, indicating an allometric effect on the variation in length (and somewhat on height) of the astragalus.

Therefore, when comparing the Vs of Thousand Creek antilocaprids (Ilingoceros and Sphenophalos) to modern species, we need to account for body size. To this end, we only compared the fossil antilocaprids to extant bovids of similar sizes. To compare fossil antilocaprids to extant bovids of similar mass, we calculated the average body mass of the genera llingoceros and Sphenophalos using the all-ruminant regression of Janis (1990). Average lengths of $\mathrm{m} 2$ for both genera were taken from Janis and Manning (1998). Body mass for 
extant taxa were obtained from the mammalian peer-reviewed literature (Nowak, 1999; Skinner and Smithers, 1990).

\section{Data Acquisition}

The dimensions of fossil astragali we measured are identical to those of DeGusta and Vrba (2003). The eight dimensions analyzed by DeGusta and Vrba (2003) describe the important details of the length, width, and thickness of the proximal and distal trochleae of the astragali (Figure 2). Dimensions were recorded to the nearest $0.01 \mathrm{~mm}$ using Mitutoyo Absolute Digimatic CD-6"C calipers, except for the MVZ and LACM specimens, which, because of tool availability, were measured with less precise Carrera Precision 6" dial calipers, recording dimensions to $0.05 \mathrm{~mm}$. To eliminate inter-operator error, all specimens were measured by EBD. To determine intra-operator error, EBD remeasured 39 specimens from UCMP, with four weeks between measurements.

All statistical analyses were rerun without the data from the LACM collections (measured with the less precise calipers), and differences in results are reported where they are present.

\section{Data Analysis}

We analyzed the eight dimensions of the astragali using the statistical package JMP (Version 8.0.2, SAS Institute) and formulas written in MS Excel. The distributions of the data were analyzed for each of the eight individual characters using the Shapiro-Wilk W test of normality (Shapiro and Wilk, 1965) and for the entire group of measurements using a principal components analysis. If the Thousand Creek antilocaprids segregated by size, it might be represented by a multimodal distribution in the first principal component (size and size-related shape differences) or in the original measurements of the astragalar dimensions. If, on the other hand, they had little size difference, they might still segregate by astragalus shape, which would be distinguishable in the first and second principal components, which would represent sizerelated and size-independent differences, respectively, in shape across the sample (Hammer and Harper, 2006). A truly multimodal distribution is only rarely distinguishable in these sorts of continuous data (Carrasco, 2004), so the failure to distinguish a distribution from normal should not be seen as a rejection of the alternate hypothesis: it only means that new specimens cannot be identified using an a priori distinction based on size.
To test the potential for these multivariate data to distinguish two closely related species, we subjected the DeGusta and Vrba (2003) African antelope data to a discriminant function analysis (DFA) on the basis of specific identification. Additionally, we performed individual DFAs within genera of African antelope, to detect the sensitivity of the astragalar dimensions to species-level differences within a genus. While these DFAs are not identical to the PCA we performed on the Thousand Creek data, they do provide a baseline for taxonomic discrimination using artiodactyl astragali. Unfortunately, we cannot perform such a DFA on extant antilocaprids because there is only the single extant species.

If there are two or three species of antilocaprids in the fossil sample, the $V$ will be larger in the fossil sample from Thousand Creek than in the single-species samples of Antilocapra americana, Texoceros guymonensis, or the samples published by DeGusta and Vrba (2003) or Weinand (2007) (Simpson, 1947; Sokal and Braumann, 1980; Carrasco, 1998). To test this prediction, we followed the methods for comparing $V$ presented by Sokal and Braumann (1980), using $V^{*}$, the coefficient of variation corrected for sample size. This correction is small and, although arguments have been presented against it on the basis that it increases the estimate of variation (Cope and Lacy, 1992; Cope, 1993), it does not change the results (Table 1) of this study and has been used here for consistency with the method of Sokal and Braumann (1980). To remove erroneously high $V^{*}$ values, we only included single-species samples from DeGusta and Vrba (2003) and Weinand (2007) with sample sizes greater than five individuals.

If coefficients of variation between the Thousand Creek sample and the single species samples are not significantly different, we cannot reject the null hypothesis that the Thousand Creek antilocaprids are members of a single species. If there are no detectible differences within the sample of astragali from Thousand Creek through both (1) exploration of the data using principal components analysis and (2) hypothesis testing using the analysis of coefficients of variation, we will be unable to reject the null hypothesis of a single species.

We also considered analyzing the Thousand Creek dataset using the environmentally-based discriminant function for bovid astragali developed by DeGusta and Vrba (2003). Before we could take that step, we first had to test whether the bovid antelope discriminant function would give sensible results when applied to a known species of antilo- 
TABLE 1. Summary statistics of astragali samples.

\begin{tabular}{|c|c|c|c|c|c|c|c|c|}
\hline & & $\mathrm{n}$ & mean & std dev & S-W1 & $v^{2}$ & $V * 3$ & $S_{V^{*}} 4$ \\
\hline \multirow{8}{*}{ 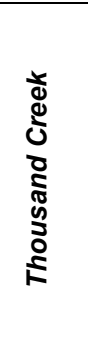 } & LM & 190 & 27.83 & 1.71 & n.s. & 0.0614 & 0.0615 & 0.0032 \\
\hline & TD & 211 & 13.99 & 1.25 & n.s. & 0.0893 & 0.0895 & 0.0044 \\
\hline & TI & 216 & 15.30 & 1.27 & n.s. & 0.0830 & 0.0831 & 0.0040 \\
\hline & TP & 212 & 11.06 & 0.97 & n.s. & 0.0877 & 0.0878 & 0.0043 \\
\hline & LL & 198 & 30.51 & 2.05 & n.s. & 0.0672 & 0.0673 & 0.0034 \\
\hline & WD & 193 & 18.62 & 1.59 & 0.0153 & 0.0854 & 0.0855 & 0.0044 \\
\hline & WI & 201 & 17.71 & 1.60 & n.s. & 0.0903 & 0.0905 & 0.0046 \\
\hline & $\mathrm{LI}$ & 215 & 23.88 & 1.58 & n.s. & 0.0662 & 0.0662 & 0.0032 \\
\hline \multirow{8}{*}{ 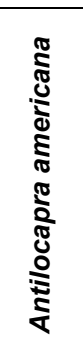 } & $\overline{L M}$ & 26 & 34.15 & 1.24 & n.s. & 0.0363 & 0.0367 & 0.0052 \\
\hline & TD & 24 & 16.70 & 1.02 & n.s. & 0.0611 & 0.0617 & 0.0092 \\
\hline & $\mathrm{TI}$ & 25 & 18.81 & 0.84 & n.s. & 0.0447 & 0.0451 & 0.0066 \\
\hline & TP & 26 & 13.90 & 0.63 & n.s. & 0.0453 & 0.0458 & 0.0065 \\
\hline & LL & 25 & 36.72 & 1.44 & 0.0039 & 0.0392 & 0.0396 & 0.0058 \\
\hline & WD & 26 & 21.91 & 0.80 & 0.0428 & 0.0365 & 0.0369 & 0.0053 \\
\hline & WI & 26 & 22.39 & 1.04 & n.s. & 0.0464 & 0.0469 & 0.0067 \\
\hline & $\mathrm{LI}$ & 25 & 28.93 & 1.06 & 0.0357 & 0.0366 & 0.0370 & 0.0054 \\
\hline \multirow{8}{*}{ 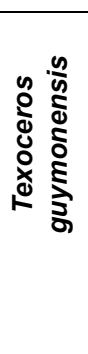 } & LM & 67 & 22.75 & 1.02 & n.s. & 0.0448 & 0.0450 & 0.0039 \\
\hline & TD & 67 & 11.51 & 0.96 & n.s. & 0.0834 & 0.0837 & 0.0074 \\
\hline & $\mathrm{TI}$ & 67 & 12.49 & 0.91 & n.s. & 0.0729 & 0.0731 & 0.0064 \\
\hline & TP & 67 & 9.39 & 0.65 & n.s. & 0.0692 & 0.0695 & 0.0061 \\
\hline & LL & 67 & 24.95 & 1.19 & n.s. & 0.0477 & 0.0479 & 0.0042 \\
\hline & WD & 67 & 15.23 & 0.90 & n.s. & 0.0591 & 0.0593 & 0.0052 \\
\hline & WI & 65 & 14.46 & 1.10 & n.s. & 0.0761 & 0.0764 & 0.0068 \\
\hline & $\mathrm{LI}$ & 65 & 19.92 & 1.08 & n.s. & 0.0542 & 0.0544 & 0.0048 \\
\hline
\end{tabular}

1 Significance of deviation from normal distribution using a Shapiro-Wilk test.

2 Coefficient of Variation.

${ }^{3} \mathrm{~V}$ corrected for sample size.

4 Standard Error of $V^{*}$.

caprid. Consequently, we analyzed our measurements of $A$. americana using the bovid antelope discriminant function (Appendix 2).

\section{RESULTS}

\section{Intra-Operator Error}

Reassuringly, the intra-operator error is much smaller than the differences in size critical to the analysis. There was a maximum disparity of 2.32 $\mathrm{mm}(13 \%)$ between individual measurements (for distal thickness of UCMP 153964), but overall average disparity was only $0.24 \mathrm{~mm}(1 \%)$. Distal thickness (TD) was the most variable dimension, with an average difference of $0.65 \mathrm{~mm}(4 \%)$. Although we did not attempt to estimate dimensions from missing parts of specimens, the distallateral corner of many astragali was abraded in a way that made the bone surface irregular. These irregular surfaces contributed to the large intraoperator error for TD. The average disparities for the other seven measurements were less than $3 \%$, an acceptable level for this analysis (Table 2), because these differences represent on the order of $10 \%$ (for most of the dimensions) of the standard deviation for the Thousand Creek sample.

TABLE 2. Intra-operator error for astragalar dimensions.

\begin{tabular}{ccc} 
Dimension & $\begin{array}{c}\text { Difference } \\
(\mathbf{m m})\end{array}$ & $\begin{array}{c}\text { Difference } \\
\mathbf{( \% )}\end{array}$ \\
\hline LM & 0.12 & 0.4 \\
TD & 0.65 & 4.5 \\
TI & 0.36 & 2.3 \\
TP & 0.14 & 1.3 \\
LL & 0.11 & 0.4 \\
WD & 0.15 & 0.8 \\
WI & 0.24 & 1.3 \\
LI & 0.12 & 0.5
\end{tabular}



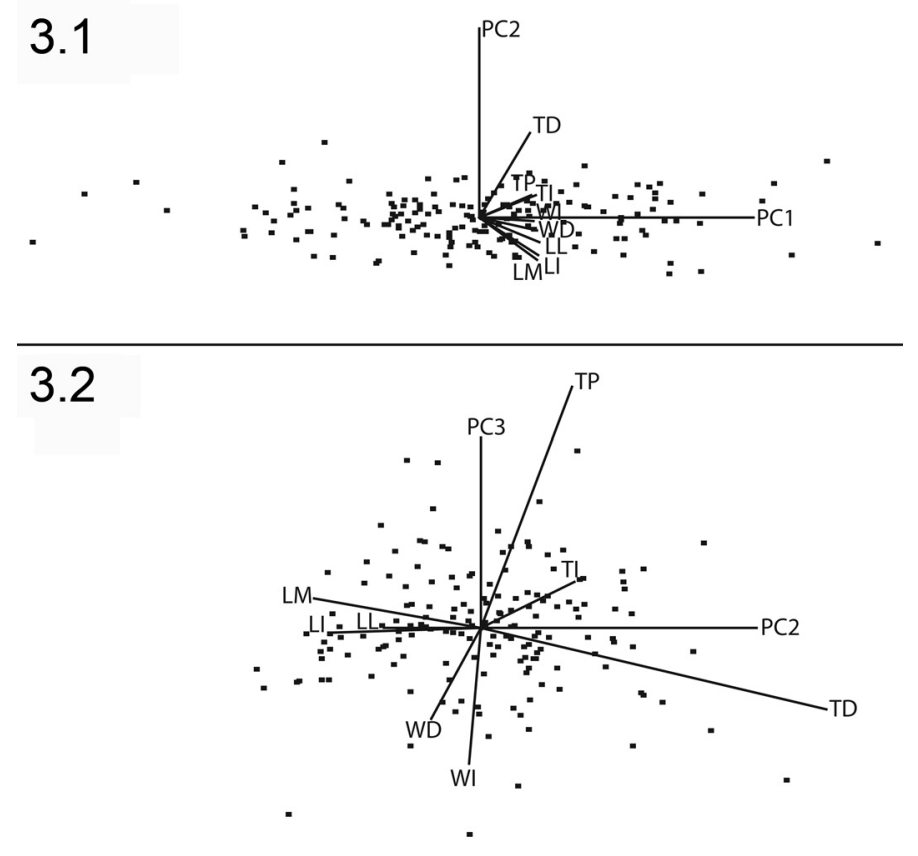

FIGURE 3. Principal components plots of Thousand Creek Antelope data. 3.1, PC1 versus PC2; 3.2 , PC2 versus PC3.

Similarly low relative errors were found in a comparison between measurements taken with the coarse $(0.05 \mathrm{~mm})$ and fine $(0.01 \mathrm{~mm})$ calipers. EBD measured 47 UCMP specimens with both sets of calipers to quantify the loss in precision with the coarser calipers. Average disparity between measurements at $0.01 \mathrm{~mm}$ and $0.05 \mathrm{~mm}$ precision was $0.32 \mathrm{~mm}$, comparable to the intra-operator error for the more precise calipers.

\section{Taxonomic Discriminant Function Analysis of African Bovid Data}

For the overall DFA, including all African bovid specimens, the analysis was able to correctly discriminate $82.11 \%$ of specimens at the species level. In comparison, DeGusta and Vrba (2003) were only able to get $67 \%$ correct for their four habitat categories. DFAs within Cephalophus, Connochaetes, Damaliscus, Oryx, and Redunca correctly distinguished all individuals; only in Kobus and Tragelaphus were there incorrect assignments. In Kobus, only one out of the 18 specimens was misclassified (Kobus megaceros placed in Kobus kob), for a $94.4 \%$ success rate. In Tragelaphus, six out of 51 specimens were misclassified (one Tragelaphus euryceros as Tragelaphus strepiceros; one Tragelaphus scriptus as Tragelaphus spekei; and three Tragelaphus strepiceros, one as Tragelaphus angazi and two as Tragelaphus euryceros) for an $88.24 \%$ success rate.

\section{Habitat Discriminant Function Applied to Antilocapra americana}

The results of the bovid discriminant function analysis on Antilocapra americana $(\mathrm{n}=26)$ included estimated body weight and predicted habitat. The habitat classification used follows Kappelman et al. (1997). Results yielded three individuals (six elements; three right and three left astragali) with a predicted habitat for the right astragalus different from that predicted for the left one within the individual (Appendix 2). In addition, all four habitat classes were predicted for at least one of the included specimens.

\section{Principal Components Analysis}

Examination of the principal components plot reveals no evidence that the distribution of Thousand Creek astragali is multimodal in any of the first three components (Figure 3 ). The first component of the PCA (PC1) accounts for $81.59 \%$ of the variation, PC2 accounts for $5.27 \%$, and PC3 for $4.38 \%$ (Table 3 ). Examination of the relative weights of the principal components indicates that because all the loads on PC1 are positive and equal, we can interpret it as changes in size (Hammer and Harper, 2006). 
TABLE 3. First three principal components of Thousand Creek antilocaprid astragali.

\begin{tabular}{cccc} 
& PC1 & PC2 & PC3 \\
\hline \multirow{2}{*}{ Eigenvalue } & Size variation & Size-independent variation in shape \\
Percent & 6.5276 & 0.4219 & 0.3504 \\
& 81.5945 & 5.2741 & 4.3795 \\
LM & 0.3651 & Eigenvectors \\
TD & 0.3178 & -0.3738 & 0.0965 \\
TI & 0.3590 & 0.7765 & -0.2646 \\
TP & 0.3284 & 0.2098 & 0.1506 \\
LL & 0.3764 & 0.2069 & 0.7848 \\
WD & 0.3631 & -0.2173 & 0.0021 \\
WI & 0.3450 & -0.1106 & -0.2944 \\
LI & 0.3692 & -0.0260 & -0.4419 \\
\end{tabular}

The first principal component (PC1) explains $82 \%$ of the total sample variance, suggesting that most of the variation in the sample is related to size. All eight of the dimensions are relatively evenly weighted in PC1, with their eigenvectors confined to the range $0.31-0.37$. The largest of the eigenvectors belong to the length dimensions, indicating that larger astragali are slightly elongated in the proximal-distal direction.

Size-independent variation in shape, if it exists, is indicated by the second and third principal components (PC2 and PC3) (Mauk et al., 1999). The Thousand Creek antilocaprid sample indicates that the largest amount of size-independent shape variation is driven by the increase of the TD and the decrease of the medial length (LM), lateral length (LL), and intermediate length (LI) of the astragali (Table 3). TD was also the measure most subject to repeatability problems, brought about by preferential taphonomic wear of the astragali, as explained in the section on Intra-Operator Error. Overall, the second component of the analysis contrasts shorter, thicker astragali with longer, thinner astragali, without much change in width. The third principal component is heavily positively weighted by proximal thickness (TP) and heavily negatively weighted by intermediate width (WI). PC3 contrasts astragali with thick proximal ends and thin centers against astragali with thin proximal ends and thick centers.

\section{Tests for Normality}

Shapiro-Wilk tests (Shapiro and Wilk, 1956; Zar, 1999) indicate that none of the Thousand Creek measurements deviate significantly from normal distributions except for distal width (WD: $\mathrm{p}=0.0153$, Table 1). A. americana deviates from normality for LL, WD, and LI. These deviations in A. americana are apparently driven by sexual dimorphism, with female specimens smaller than all male specimens. This degree of sexual dimorphism is typical of ruminants. The variance from dimorphism should not impact the results because all analyses are run at the species level with datasets that include both males and females. T. guymonensis does not deviate from normality for any of its dimensions. Because there is no sign of bimodality in the distribution of Thousand Creek astragali, this part of the analysis cannot reject the null hypothesis of a single biological species. Additionally, individual astragali cannot be assigned to particular taxa based on their dimensions.

\section{Coefficient of Variation $\left(V^{*}\right)$}

We find Ilingoceros and Sphenophalos to be small antilocaprids with average body masses of 56.6 and $39.4 \mathrm{~kg}$, respectively. Extant bovids of similar body sizes include Aepyceros melampus, Antidorcas marsupialis, Gazella granti, and Tragelaphus scriptus (Nowak, 1999; Skinner and Smithers, 1990). Antilocapra americana is also in the same size range (around $50 \mathrm{~kg}$; O'Gara, 1978). We also compared the Thousand Creek fossils to another fossil, Texoceros guymonensis. Tragelaphus scriptus is the bovid with the largest coefficients of variation (among all small extant bovids considered and for all variables); interestingly, it is also the only forest-dwelling form of all of the animals, extinct and extant, included in our analysis. There is no significant difference between the coefficient of variation of Tr. scriptus (a single species) and that of the Thousand Creek fossil assemblage (Table 4). In a comparison between the Thousand Creek assemblage and the species with the smallest coefficients of variation (G. granti), two variables are not significantly different (LM and TP), but $G$. granti is significantly lower for the other six (Table 4). Comparison with the other two species is 
TABLE 4. Summary statistics of Bovid astragali.

\begin{tabular}{|c|c|c|c|c|c|c|c|c|}
\hline Species & & mean & sd & V & $\mathbf{V}^{*}$ & s.e. $V^{*}$ & $V^{*}-1 \mathrm{kCr} V^{*}$ & $p$ \\
\hline Aepyceros melapus & LM & 35.04 & 1.410 & 0.0402 & 0.0412 & 0.0103 & -1.61 & 0.109 \\
\hline \multirow[t]{7}{*}{$n=10$} & TD & 16.53 & 1.036 & 0.0627 & 0.0642 & 0.0164 & -1.49 & 0.138 \\
\hline & $\mathrm{TI}$ & 19.20 & 0.894 & 0.0466 & 0.0477 & 0.0120 & -2.79 & 0.006 \\
\hline & TP & 13.76 & 0.660 & 0.0480 & 0.0492 & 0.0124 & -2.94 & 0.004 \\
\hline & LL & 37.42 & 1.580 & 0.0422 & 0.0433 & 0.0109 & -2.11 & 0.036 \\
\hline & WD & 21.78 & 0.900 & 0.0413 & 0.0424 & 0.0106 & -3.75 & 0.000 \\
\hline & WI & 21.86 & 0.903 & 0.0413 & 0.0424 & 0.0106 & -4.16 & 0.000 \\
\hline & LI & 28.94 & 1.195 & 0.0413 & 0.0423 & 0.0106 & -2.15 & 0.032 \\
\hline Antidorcas marsupialis & LM & 28.16 & 1.637 & 0.0581 & 0.0599 & 0.0174 & -0.09 & 0.930 \\
\hline \multirow[t]{7}{*}{$n=8$} & TD & 13.58 & 1.193 & 0.0879 & 0.0906 & 0.0269 & 0.04 & 0.967 \\
\hline & TI & 15.73 & 1.043 & 0.0663 & 0.0684 & 0.0199 & -0.72 & 0.470 \\
\hline & TP & 11.16 & 0.938 & 0.0841 & 0.0867 & 0.0256 & -0.04 & 0.966 \\
\hline & LL & 30.25 & 1.739 & 0.0575 & 0.0593 & 0.0172 & -0.46 & 0.647 \\
\hline & WD & 18.79 & 1.132 & 0.0602 & 0.0621 & 0.0180 & -1.26 & 0.209 \\
\hline & WI & 18.81 & 1.499 & 0.0797 & 0.0822 & 0.0242 & -0.34 & 0.736 \\
\hline & LI & 23.66 & 1.349 & 0.0570 & 0.0588 & 0.0170 & -0.43 & 0.669 \\
\hline Gazella granti & LM & 33.80 & 1.340 & 0.0396 & 0.0406 & 0.0102 & -1.96 & 0.052 \\
\hline \multirow[t]{7}{*}{$n=10$} & TD & 17.04 & 0.837 & 0.0491 & 0.0503 & 0.0127 & -2.91 & 0.004 \\
\hline & $\mathrm{TI}$ & 19.08 & 0.842 & 0.0441 & 0.0452 & 0.0114 & -3.15 & 0.002 \\
\hline & TP & 13.33 & 0.943 & 0.0707 & 0.0725 & 0.0186 & -0.80 & 0.424 \\
\hline & LL & 36.74 & 1.503 & 0.0409 & 0.0419 & 0.0105 & -2.30 & 0.023 \\
\hline & WD & 21.95 & 0.920 & 0.0419 & 0.0430 & 0.0108 & -3.65 & 0.000 \\
\hline & WI & 20.79 & 0.794 & 0.0382 & 0.0391 & 0.0098 & -4.75 & 0.000 \\
\hline & LI & 28.65 & 1.154 & 0.0403 & 0.0413 & 0.0103 & -2.30 & 0.022 \\
\hline Tragelaphus scriptus & LM & 33.6 & 2.729 & 0.08122 & 0.08291 & 0.01937 & 1.09 & 0.277 \\
\hline \multirow[t]{7}{*}{$n=12$} & TD & 15.23 & 1.495 & 0.09816 & 0.10021 & 0.02373 & 0.44 & 0.658 \\
\hline & $\mathrm{TI}$ & 18.03 & 1.597 & 0.08857 & 0.09042 & 0.02125 & 0.34 & 0.735 \\
\hline & TP & 13.41 & 1.25 & 0.09321 & 0.09516 & 0.02244 & 0.32 & 0.748 \\
\hline & $\mathrm{LL}$ & 35.73 & 3.106 & 0.08693 & 0.08874 & 0.02083 & 1.02 & 0.311 \\
\hline & WD & 21.23 & 1.903 & 0.08964 & 0.0915 & 0.02152 & 0.27 & 0.785 \\
\hline & WI & 19.59 & 1.987 & 0.10143 & 0.10354 & 0.02458 & 0.52 & 0.603 \\
\hline & LI & 28.96 & 2.539 & 0.08767 & 0.0895 & 0.02102 & 1.10 & 0.274 \\
\hline
\end{tabular}

split, with $A$. marsupialis showing no significant differences, but $A$. melapus showing six values significantly lower than Thousand Creek (Table 4). The test of differences between $V^{*}$ indicates that Thousand Creek antilocaprids are significantly more variable than $A$. americana in all dimensions and are also more variable than $T$. guymonensis in five of eight dimensions (Table 5, Figure 4). Addition- ally, T. guymonensis is more variable than $A$. americana in five of eight dimensions.

\section{DISCUSSION}

Our multivariate analysis of antilocaprid astragali from Thousand Creek cannot distinguish among the three species diagnosed by horncores. Consequently, either: (1) the analyzed astragali are 
TABLE 5. Comparison of $V^{*}$, following Sokal and Braumann (1980).

\begin{tabular}{|c|c|c|c|c|c|c|c|}
\hline & & & $V^{*}{ }_{1}-V^{*}{ }_{2}{ }^{1}$ & $S_{V * 1-V^{*} 2}$ & $\mathrm{df}^{3}$ & $t^{4}$ & p \\
\hline \multirow{8}{*}{ 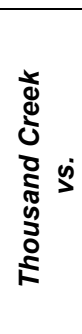 } & \multirow{8}{*}{ 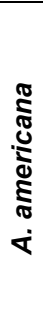 } & LM & 0.0249 & 0.0061 & 214 & 4.0560 & $<0.0001$ \\
\hline & & TD & 0.0277 & 0.0102 & 233 & 2.7131 & 0.0072 \\
\hline & & $\mathrm{TI}$ & 0.0380 & 0.0077 & 239 & 4.9170 & $<0.0001$ \\
\hline & & TP & 0.0420 & 0.0078 & 236 & 5.3637 & $<0.0001$ \\
\hline & & LL & 0.0277 & 0.0067 & 221 & 4.1217 & $<0.0001$ \\
\hline & & WD & 0.0486 & 0.0069 & 217 & 7.0840 & $<0.0001$ \\
\hline & & WI & 0.0436 & 0.0081 & 225 & 5.3675 & $<0.0001$ \\
\hline & & $\mathrm{LI}$ & 0.0292 & 0.0063 & 238 & 4.6488 & $<0.0001$ \\
\hline \multirow{8}{*}{ 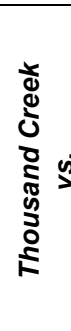 } & \multirow{8}{*}{ 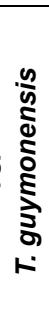 } & LM & 0.0165 & 0.0051 & 255 & 3.2634 & 0.0013 \\
\hline & & TD & 0.0057 & 0.0086 & 276 & 0.6687 & n.s. \\
\hline & & $\mathrm{TI}$ & 0.0100 & 0.0076 & 281 & 1.3144 & n.s. \\
\hline & & TP & 0.0183 & 0.0075 & 277 & 2.4535 & 0.0148 \\
\hline & & LL & 0.0194 & 0.0054 & 263 & 3.5911 & 0.0004 \\
\hline & & WD & 0.0262 & 0.0068 & 258 & 3.8444 & 0.0002 \\
\hline & & WI & 0.0141 & 0.0082 & 264 & 1.7181 & n.s. \\
\hline & & LI & 0.0118 & 0.0058 & 278 & 2.0317 & 0.0431 \\
\hline \multirow{8}{*}{\multicolumn{2}{|c|}{ 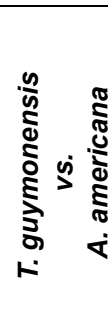 }} & $\overline{L M}$ & 0.0083 & 0.0066 & 91 & 1.2725 & n.s. \\
\hline & & TD & 0.0220 & 0.0118 & 89 & 1.8637 & n.s. \\
\hline & & $\mathrm{TI}$ & 0.0280 & 0.0092 & 90 & 3.0462 & 0.0030 \\
\hline & & TP & 0.0237 & 0.0089 & 91 & 2.6512 & 0.0095 \\
\hline & & LL & 0.0083 & 0.0071 & 90 & 1.1573 & n.s. \\
\hline & & WD & 0.0225 & 0.0074 & 91 & 3.0323 & 0.0032 \\
\hline & & WI & 0.0295 & 0.0096 & 89 & 3.0813 & 0.0027 \\
\hline & & $\mathrm{LI}$ & 0.0174 & 0.0073 & 88 & 2.4009 & 0.0185 \\
\hline
\end{tabular}

Differences in coefficients of variation.

2 Standard Error of difference.

3 Degrees of freedom.

$4 V^{*}{ }_{1}-V^{*}{ }_{2} / S_{V^{*} 1-V^{*}}$.

derived from only one of the species described from horncores; (2) the horn core morphologies do not reflect specific differences; or (3) the species do not partition their resources in a way that is reflected by their astragali. Possibility (1) is extremely unlikely, because the sample size for astragali $(n=223)$ is an order of magnitude larger than that for horncores $(n=17)$. There are seven Sphenophalos and 10 llingoceros horncores in the curated Thousand Creek collections of the UCMP. Assuming that the 136 astragali in the UCMP collections were from only one of those taxa produces a chi-square value of $95.2(p<0.0001)$. Possibility (2) is unlikely based on independent occurrences of Sphenophalos without Ilingoceros. Assuming that Furlong's (1932) specimens of Sphenophalos from deposits in Malheur County, Oregon, are a random subsample of a population including both forms (but recording only one) produces a chisquare value of $7.143(p<0.01)$ when compared to the distribution of horncores from both forms in Thousand Creek.
In addition, we can rule out possibilities 1 and 2 because our $V^{*}$ comparison indicates that the Thousand Creek sample has greater variation than that expected from a single species assemblage. Clearly there is a great deal of variation in $V^{*}$ values between extant antelope species in the size range of llingoceros and Sphenophalos, as seen in the non-significance of a comparison between the Thousand Creek sample and Tragelaphus scriptus; however, because of the influence of evolutionary history (see results of DFA), it is best to limit comparisons to the narrowest evolutionary distance possible, in this case between the Thousand Creek sample and $T$. guymonensis and $A$. americana. Comparing the dispersion of variables in fossil species with those of extant populations is a standard procedure in paleontology; however, five measurements of the known single-species fossil sample of $T$. guymonensis are more variable than those of the extant $A$. americana, suggesting caution when interpreting the variance of fossil species. T. guymonensis is approximately the same size as the Thousand Creek antilocaprids and smaller than $A$. 


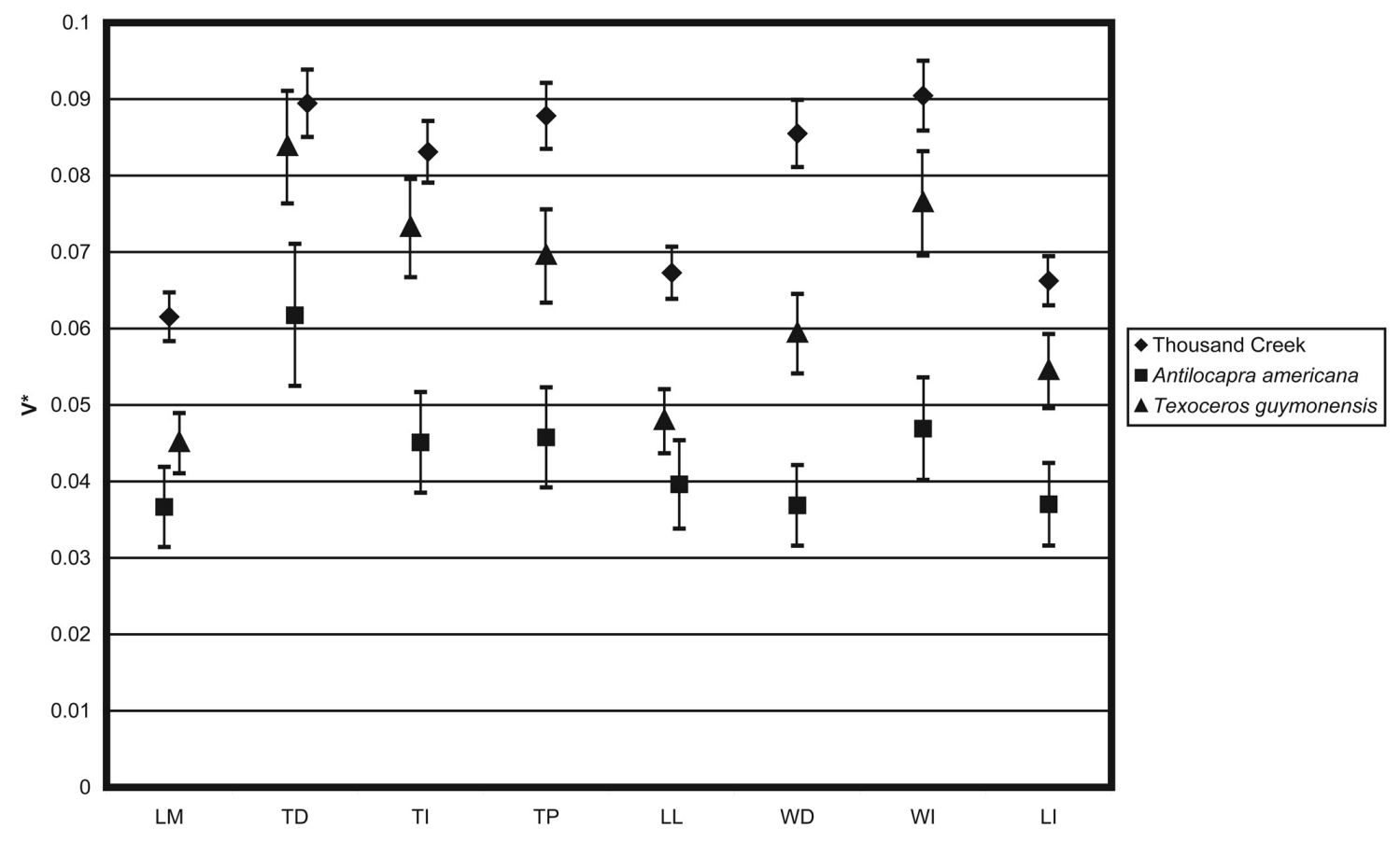

FIGURE 4. Comparison of values of $V^{*}$ for the Thousand Creek antilocaprids, Texoceros guymonensis, and Antilocapra americana. Vertical bars represent $95 \%$ confidence intervals.

americana, so its high $V^{*}$ is not caused by a higher body-mass. Additionally, T. guymonensis shows a unimodal distribution, so it is not likely to be more sexually dimporphic than $A$. americana. In this case, the time-averaging of the Optima fossil assemblage seems to have produced greater overall variance than averaging across the entire geographic range of extant $A$. americana; consequently, the safest comparison is between the unknown fossil assemblage (Thousand Creek) and the known single-species fossil assemblage (Optima). The Thousand Creek sample is significantly higher than $T$. guymonensis, suggesting we should reject the null hypothesis of one species. Optima and Thousand Creek appear to have similar sampling regimes, in terms the quality of preservation, but we cannot be sure they share similar amounts of time averaging. We tentatively reject the one-species hypothesis, but the influence of time-averaging on $V^{*}$ indicates a final decision must await a more complete analysis of the relative amounts of time-averaging in the Thousand Creek and Optima faunas.

This leaves a possibility (3) that the animals were not sufficiently different in their astragalus ecomorphology for discrimination because the species had ecologies that did not dramatically differ in a way reflected in their astragali. It is possible that subtle differences not found in the PCA would be uncovered with a DFA; however, the lack of a training set of known Ilingoceros and Sphenophalos astragali means DFA cannot be used to analyze our Thousand Creek dataset. Additionally, those subtle differences are expected to be in shape and should, therefore, be reflected in the PCA.

The normal distributions of the measurements of the Thousand Creek and the Texoceros guymonensis samples contrast with the bimodal distributions of the modern Antilocapra americana. Antilocapra americana presents sexual dimorphism in both body size and horn morphology (O'Gara, 1978), although the body size dimorphism is not extreme. The normal distributions of the fossil samples suggest three possibilities: 1) these fossil taxa were not sexually dimorphic, at least for body size, 2) they were dimorphic but enough time is averaged in the sample to obscure it, or 3) for Thousand Creek there are two dimorphic species represented, with the males of the small species fitting between the sexes of the larger species. We cannot currently distinguish between these possibilities. The lack of natural morphological breaks among the Thousand Creek astragali means that we cannot resolve the argument over whether Ilin- 
goceros schizoceras is merely a juvenile or female form of $I$. alexandrae or a valid species. Final resolution of this question awaits a morphometric analysis of the horncores of $I$. schizoceras and $I$. alexandrae. This avenue of investigation should examine whether the shape of the $I$. alexandrae horn core could ontogenetically and allometrically follow from that of $I$. schizoceras, expanding on the work of Raup and Michelson (1965; Raup, 1966, 1967) with gastropod and cephalopod mollusk shell coiling and Gould's (1974) work on cervid antler growth.

In the absence of size or astragalar-shape distinctions, how could Ilingoceros and Sphenophalos coexist without the competitive exclusion of one taxon? Apparent ecological overlap could simply be a consequence of the coarseness of astragalar shape as a proxy for morphological differentiation, but the difference in horn core morphologies of llingoceros and Sphenophalos suggests that their species distinctions may have been more social than ecological. The spiraling horns of llingoceros, convergent on those of the African bovid Tragelaphus, suggest a focus of the attacks of aggressive males into wrestling matches, reducing the likelihood of serious injury from sparring (Geist, 1966; Lundrigan, 1996; Caro et al., 2003). The shorter, forked horncores of Sphenophalos, very similar to those of Antilocapra (Furlong, 1932; Barbour and Schultz, 1941), are associated with most confrontations leading to withdrawal, because actual fights are violent and lead to injury of one or both combatants (Geist, 1966; Lundrigan, 1996; Caro et al., 2003). Although it appears that llingoceros and Sphenophalos were very similar in size and aspects of their ecology reflected in astragalar morphology, male-male competition may have been different for the two taxa.

The apparent inapplicability of the bovid habitat discriminant function to $A$. americana suggests that physical constraints on bovid and antilocaprid astragalar functional morphology are overridden by evolutionary history and consequent developmental constraints on astragalus morphology. The discriminant function of DeGusta and Vrba (2003) is apparently only characteristic of bovid antelope and should not be directly applied to antilocaprids or, potentially, any other family of artiodactyls, because it will make erroneous predictions, colored by the evolutionary history of bovids and African antelopes. After considering these results, we declined to test the refined discriminant function of Weinand (2007) that also includes southeast Asian bovids, because it would be subject to the same historical constraints as that of DeGusta and Vrba (2003).

\section{CONCLUSION}

There is more variance in the astragalus dimensions of Thousand Creek antilocaprids than expected in comparison to a sample of extant Antilocapra americana or a similar fossil sample of a single species, Texoceros guymonensis, but there are not obvious breaks in the size distribution that would permit diagnosis of individual species. The normal, unimodal distribution of the Thousand Creek sample likely reflects an overlap in size between the largest individuals of the small-bodied species and the smallest individuals of the largebodied species, or, potentially, size overlap among three species, if llingoceros schizoceras is valid. Statistical samples from two or more normally distributed populations may produce a single unimodal sample even if the population means are not close together (Plavcan, 1993). The presence of different source populations can then be inferred only on the basis of the unusually high variance of the sample (Simpson, 1947; Sokal and Braumann, 1980; Carrasco, 1998), as observed in the Thousand Creek antilocaprids. Thus, recognition of which astragali belong to which species is limited to only the largest and smallest astragali-that is, astragali that fall in the extreme upper and lower $\sim 5 \%$ of the distribution, but little can be said with confidence of the middle 90\% (Appendix 1).

The results presented here indicate that Sphenophalos and llingoceros were similar in body size and astragalar shape, possibly indicating similar levels of agility and habitat preference for the two genera. Differences in the horn morphologies of the two genera probably reflect differences in male-male competition. The two named species of llingoceros, I. alexandrae, and I. schizoceras, may represent different age classes or sexes of a single species, but the data presented here cannot resolve the issue. This taxonomic problem awaits additional research into the growth of the Ilingoceros horn.

In conclusion, we find promise in the use of astragali to distinguish species of artiodactyls, but that promise is tempered by the reality of biological variation. Within the well-resolved modern African antelope data of DeGusta and Vrba (2003), it was possible to use astragalar measurements to distinguish species with a high level of success. If large enough known samples from a family (e.g., bovids, antilocaprids, cervids) can be used to train a DFA, 
astragali could be used to increase the sample sizes of mammalian fossil assemblages that contain members of that family. Care should be taken in construction of the training sample, choosing species that are likely to be in the time and region of the unknown fossil sample. Obviously, this method could not be used to identify new species; it will only place samples into known species. Samples identified by DFA would, in turn, improve the precision of paleoecological analyses based upon relative abundances. Unfortunately, in cases like that of Thousand Creek, where no training samples are available, the similar sizes of closely related species may preclude precise estimation of relative abundances. Maximum likelihood analysis of mixture models may help future attempts to use normally distributed measurements of postcranial elements to differentiate species (Hunt and Chapman, 2001). The strong taxonomic signal recorded in astragalar measurements also warns against applying discriminant functions derived from one broad taxonomic group to another: the habitat based DFA from DeGusta and Vrba (2003) cannot be expected to work with any other group than the African bovids upon which it was based.

While we can tentatively reject the hypothesis that there was only one species of antilocaprid at Thousand Creek, we cannot improve on the relative abundances calculated from horncores. This methodology will be most successful at extending identifications from sites of known compositions with cranial and postcranial remains to those with few or no cranial remains.

\section{ACKNOWLEDGMENTS}

We thank P. Holroyd (UCMP), C. Conroy (MVZ), S. McLeod (LACM), S. Bell (AMNH), B. Evander (AMNH), and the late R. Tedford (AMNH) for access to specimens and helpful advice. We thank S. Hopkins, B. Feranec, D. Prothero, D. Erwin, T. Barnosky, M. Carrasco, the rest of the Barnosky Lab as well as J. Orcutt for helpful criticism in the process of this research. Without the help of B. Day, N. Valentine, and others in the US FWS, EBD would not have been able collect fossil astragali in the Thousand Creek Beds of the Sheldon NWR. We would like to thank C. Janis and three anonymous reviewers for their constructive reviews of our manuscript. EBD would especially like to thank C. Hickman, B. Clemens, D. Sloan, and the rest of the board of The George D. Louderback Fund, Inc., for financing his calipers and portions of his trips to LACM and AMNH. This research began while EBD was a Graduate Research Fellow of the NSF. Additionally, the Geological Society of America provided grant money that helped finance EBD's trip to the AMNH. Part of this research was undertaken while JC was supported by an Explo'ra sup scholarship (Université Claude Bernard Lyon I).

\section{REFERENCES}

Alroy, J., Koch, P.L., and Zachos, J.C. 2000. Global climate change and North American mammalian evolution. Paleobiology,, 26 (Suppl. to No. 4):259-288.

Barbour, E.H. and Schultz, C.B. 1941. A new species of Sphenophalos from the upper Ogallala of Nebraska. Bulletin of the University of Nebraska State Museum 2:59-62.

Barnosky, A.D., Carrasco, M.A., and Davis, E.B. 2005. The impact of the species-area relationship on estimates of paleodiversity. PLoS Biology, 3:1356-1361.

Breyer, J.A. 1983. The Biostratigraphic Utility of Camel Metapodials. Journal of Paleontology, 57(2):302-307.

Caro, T.M., Graham, C.M., Stoner, C.J., and Flores, M.M. 2003. Correlates of horn and antler shape in bovids and cervids. Behavioral Ecology and Sociobiology, 55:32-41.

Carrasco, M.A. 1998. Variation and its implications in a population of Cupidinimus (Heteromyidae) from Hepburn's Mesa, Montana. Journal of Vertebrate Paleontology, 18:391-402.

Carrasco, M.A. 2004. Assessing statistical techniques for detecting multispecies samples of heteromyids in the fossil record: A test using extant Dipodomys. Bulletin of the American Museum of Natural History, 285:120-129.

Carrasco, M.A., Kraatz, B.P., Davis, E.B., and Barnosky, A.D. 2005. Miocene Mammal Mapping Project (MIOMAP). University of California Museum of Paleontology. http://www.ucmp.berkeley.edu/miomap/

Cope, D.A. 1993. Measures of dental variation as indicators of multiple taxa in samples of sympatric Cercopithecus species, p. 211-237. In Kimbel, W.H. and Martin, L.B. (eds.), Species, Species Concepts, and Primate Evolution. New York: Plenum Press.

Cope, D.A. and Lacy, M.G. 1992. Falsification of a single species hypothesis using the coefficient of variation: a simulation approach. American Journal of Physical Anthropology, 89:359-378.

Davis, E.B. 2004. Identification of mammalian postcrania using multivariate analysis: classifying astragali of Camelidae (Mammalia) from the late Miocene of Nevada. Geological Society of America Abstracts with Programs, 36(5):315.

Davis, E.B. 2005. Mammalian beta diversity in the Great Basin, western USA: Palaeontological data suggest deep origin of modern macro-ecological structure. Global Ecology and Biogeography, 14:479-490. 
Davis, E.B. 2007. Family Antilocapridae. p. 227-240. In Prothero, D.R. and Foss, S.E. (eds.), The Evolution of Artiodactyls. Johns Hopkins University Press, Baltimore, Maryland.

Davis, E.B. and Pyenson, N.D. 2007. Diversity biases in terrestrial mammalian assemblages and quantifying the differences between museum collections and published accounts: A case study from the Miocene of Nevada. Palaeogeography, Palaeoclimatology, Palaeoecology, 250:139-149.

DeGusta, D. and Vrba, E. 2003. A method for inferring paleohabitats from the functional morphology of bovid astragali. Journal of Archaeological Science, 30:1009-1022.

Finarelli, J.A. and Badgley, C. 2010. Diversity dynamics of Miocene mammals in relation to the history of tectonism and climate. Proceedings of the Royal Society B 277:2721-2726.

Frick, C. 1937. Horned ruminants of North America. Bulletin of the American Museum of Natural History, 69:1-669.

Furlong, E.L. 1932. Distribution and description of skull remains of the Pliocene antelope Sphenophalos from the northern Great Basin Province. Contributions to Paleontology, Carnegie Institution of Washington. 418:27-36.

Geist, V. 1966. The evolution of horn-like organs. Behaviour, 27:175-214.

Gould, S. J. 1974. The origin and function of "bizarre" structures: Antler size and skull size in the "Irish elk," Megaloceros giganteus. Evolution, 28:191-220.

Green, R.C. 1984. Geologic appraisal of the Charles Sheldon Wilderness Study Area, Nevada and Oregon. Geological Survey Bulletin, 1538:13-34.

Hammer, $\varnothing$. and Harper, D. 2006. Paleontological Data Analysis. Blackwell Publishing, Oxford.

Hunt, G. and Chapman, R.E. 2001. Evaluating hypotheses of instar-grouping in arthropods: a maximum likelihood approach. Paleobiology, 27:466-484.

Janis, C.M. 1990. Correlation of cranial and dental variables with body size in ungulates and macropodoids. p. 255-300. In Damuth, J. and MacFadden, B.J. (eds.), Body Size in Mammalian Paleobiology, Estimation and Biological Implications. Cambridge University Press, Cambridge.

Janis, C.M. and Manning, E. 1998. Antilocapridae, p. 491-507. In Janis, C.M., Scott, K.M., and Jacobs, L.L. (eds.), Evolution of Tertiary Mammals of North America. Volume 1: Terrestrial Carnivores, Ungulates, and Ungulatelike Mammals. Cambridge University Press, Cambridge.

Janis, C.M., Scott, K.M., and Jacobs, L.L., eds. 1998. Evolution of Tertiary Mammals of North America. Vol. 1: Terrestrial Carnivores, Ungulates, and Ungulatelike Mammals. New York: Cambridge University Press.
Kappelman, J., Plummer, T.W., Bishop, L.C., Duncan, A., and Appleton, S. 1997. Bovids as indicators of PlioPleistocene paleoenvironments in East Africa. Journal of Human Evolution, 32:229-256.

Kohn, M.J. and Fremd, T.J. 2008. Miocene tectonics and climate forcing of biodiversity, Western United States. Geology, 36:783-786.

Krause, D.W. 1986. Competitive exclusion and taxonomic displacement in the fossil record: the case of rodents and multituberculates in North America. Contributions to Geology, University of Wyoming, Special paper, 3:95-117.

Lundrigan, B. 1996. Morphology of horns and fighting behavior in the family Bovidae. Journal of Mammalogy, 77:462-475.

Mauk, C.L., Houck, M.A., and Bradley, R.D. 1999. Morphometric analysis of seven species of pocket gophers (Geomys). Journal of Mammalogy, 80:499511.

Merriam, J.C. 1909. The occurrence of strepsicerine antelopes in the Tertiary of northwestern Nevada. University of California Publication in Geological Sciences, 5:319-330.

Merriam, J.C. 1911. Tertiary mammal beds of Virgin Valley and Thousand Creek in northwestern Nevada. Part II - Vertebrate faunas. University of California Publication in Geological Sciences, 6:199-304.

Merriam, J. C. and Stock, C. 1928. A further contribution to the mammalian fauna of the Thousand Creek Pliocene, northwestern Nevada. Contributions to Paleontology, Carnegie Institution of Washington, 393:5-21.

Nowak, R.M. 1999. Walker's Mammals of the World. Volume II. $6^{\text {th }}$ Edition. The Johns Hopkins University Press.

O'Gara, B.W. 1978. Antilocapra americana. Mammalian Species, 90:1-7.

Olzewski, T.D. 2004. A unified mathematical framework for the measurement of richness and evenness within and among multiple communities. Oikos, 104:377-387.

Perkins, M.E., Brown, F.H., Nash, W.P., Mclntosh, W., and Williams, S.K. 1998. Sequence, age, and source of silicic fallout tuffs in middle to late Miocene basins of the northern Basin and Range province. Geological Society of America Bulletin, 110:344-360.

Plavcan, J.M. 1993. Catarrhine dental variability and species recognition in the fossil record, p. 239-263. In Kimbel, W.H. and Martin, L.B., (eds.), Species, species concepts, and primate evolution. New York: Plenum Press.

Prothero, D.R. and Davis, E.B. 2008. Magnetic stratigraphy of the upper Miocene (early Hemphillian) Thousand Creek Formation, northwestern Nevada. Neogene Mammals, New Mexico Museum of Natural History and Science Bulletin, 44:233-237.

Raup, D.M. and Michelson, A. 1965. Theoretical morphology of the coiled shell. Science, 147:1294-1295. 
Raup, D.M. 1966. Geometric analysis of shell coiling; general problems. Journal of Paleontology, 40:11781190.

Raup, D.M. 1967. Geometric analysis of shell coiling; coiling in ammonoids. Journal of Paleontology, 41:43-65.

Schultz, G.E. 2002. Clarendonian and Hemphillian vertebrate faunas from the Ogallala Formation (Late Miocene-Early Pliocene) of the Texas Panhandle and adjacent Oklahoma, p. 35-71. In Burkhalter, R., Czaplewski, N.J., and Lupia, R., (eds.). SVP 2002 Field Trip Guidebook, 62nd Annual Meeting, Oklahoma Geological Survey Open-File Report 10-2002, Norman, Oklahoma.

Shapiro, S.S., and Wilk, M.B. 1956. An analysis of variance test for normality (complete samples). Biometrika, 52:591-611.

Shotwell, J.A. 1963. The Juntura Basin: Studies in Earth History and Paleoecology. Transactions of the American Philosophical Society, 53:1-77.
Simpson, G.G. 1947. Note on the measurement of variability and on relative variability of teeth of fossil mammals. American Journal of Science, 245:522525.

Skinner, J.D. and Smithers, R.H.N. 1990. The Mammals of the Southern African Subregion. University of Pretoria, South Africa.

Sokal, R.R. and Braumann, C.A. 1980. Significance tests for coefficients of variation and variability profiles. Systematic Zoology, 29:50-66.

Stirton, R.A. 1932. An association of horncores and upper molars of the antelope Sphenophalos nevadanus from the lower Pliocene of Nevada. American Journal of Science, 24:46-51.

Weinand, D.C. 2007. A study of parametric versus nonparametric methods for predicting paleohabitat from Southeast Asian Bovid astragali. Journal of Archaeological Science 34:1774-1783.

Zar, J.H. 1999. Biostatistical Analysis, Prentice Hall, Upper Saddle River, New Jersey. 


\section{APPENDIX 1}

List of included UCMP and LACM specimens from Thousand Creek, Nevada. Abbreviations: \#, number; R, right; L, left; I., Ilingoceros; S., Sphenophalos; LM, medial length; TD, distal thickness; TI, intermediate thickness; TP, proximal thickness; LL, lateral length; WD, distal width; WI, intermediate width; LI, intermediate length.

\begin{tabular}{|c|c|c|c|c|c|c|c|c|c|c|c|c|}
\hline Museum & Loc. \# & $\begin{array}{c}\text { Specimen } \\
\#\end{array}$ & Side & Taxon & LM & TD & TI & TP & LL & WD & WI & LI \\
\hline LACM & 3746 & 89840 & $\mathrm{~L}$ & I. or $S$. & 27.2 & 14.15 & 15.8 & 10.5 & 31.35 & 18.3 & 17.8 & 22.9 \\
\hline LACM & 3747 & 90213 & $\mathrm{R}$ & I. or $S$. & 25.9 & 12.85 & 14.3 & 10.35 & - & 17.55 & 16.2 & 21.95 \\
\hline LACM & 3747 & 90214 & $\mathrm{R}$ & I. or $S$. & 28.3 & 14.9 & 14.6 & 10.8 & 30.5 & 18 & 17.25 & 24.15 \\
\hline LACM & 5813 & 150577 & $\mathrm{R}$ & I. or $S$. & 29.3 & 13.9 & 15.5 & 11.3 & 31.9 & 18.2 & 17.4 & 24.8 \\
\hline LACM & 5813 & 150580 & L & I. or $S$. & 29 & 11.6 & 14.3 & - & - & - & 17.1 & 25.75 \\
\hline LACM & (CIT) 63 & 98343 & $\mathrm{R}$ & I. or S. & 28.05 & 12.95 & 15.5 & 10.95 & 29.9 & 19.2 & 18.7 & 23.6 \\
\hline LACM & (CIT) 63 & 98344 & $\mathrm{R}$ & I. or $S$. & - & 14.75 & 14.9 & 10.7 & 28.6 & - & 16 & 22.9 \\
\hline LACM & (CIT) 63 & 98345 & $\mathrm{R}$ & I. or $S$. & 29.2 & 15.65 & 16.65 & 12.1 & 32.2 & 19.95 & 18.5 & 25.35 \\
\hline LACM & (CIT) 63 & 98346 & $\mathrm{R}$ & I. or $S$. & 30 & 15.5 & 17.3 & 12.15 & 32.6 & 20.6 & 18.6 & 25.9 \\
\hline LACM & (CIT) 63 & 98347 & $\mathrm{R}$ & I. or $S$. & 29.7 & 14.5 & 15.9 & 12.05 & 32.55 & 20.6 & 19.9 & 25.65 \\
\hline LACM & (CIT) 63 & 98348 & $\mathrm{R}$ & I. or $S$. & 27.2 & 13.65 & 15.05 & 11.35 & 29.6 & 18.75 & 16.6 & 23.25 \\
\hline LACM & $(\mathrm{CIT}) 63$ & 98349 & $\mathrm{R}$ & I. or $S$. & 29.65 & 14.5 & 16.2 & 11.35 & 31.75 & 18.7 & - & 25.4 \\
\hline LACM & (CIT) 63 & 98350 & $\mathrm{R}$ & I. or $S$. & 28.4 & 14.75 & 16.5 & 10.85 & - & 19.7 & 20.05 & - \\
\hline LACM & (CIT) 63 & 98351 & $\mathrm{R}$ & I. or $S$. & 28.35 & 14.3 & 16.15 & 11.9 & 31.65 & 18.7 & 17.55 & 24.15 \\
\hline LACM & (CIT) 63 & 98352 & $\mathrm{R}$ & I. or $S$. & 26.35 & 13.7 & 15.35 & 10.65 & 28.6 & 17.95 & 16.7 & 22.2 \\
\hline LACM & $(\mathrm{CIT}) 63$ & 98353 & $\mathrm{R}$ & I. or $S$. & 26.7 & 13.3 & 14.7 & 10.75 & 29.6 & 17.6 & 16.85 & 22.8 \\
\hline LACM & (CIT) 63 & 98354 & $\mathrm{R}$ & I. or $S$. & - & 14.5 & 16.4 & 12.1 & 32.9 & - & - & 26 \\
\hline LACM & (CIT) 63 & 98355 & $\mathrm{R}$ & I. or $S$. & 28.3 & 13.8 & 15.3 & 11.05 & 31.05 & 19.5 & 17.15 & 24.9 \\
\hline LACM & (CIT) 63 & 98356 & $\mathrm{R}$ & I. or $S$. & 29.55 & 14.2 & 16.2 & 12 & 31.8 & 19.9 & 18 & 25.2 \\
\hline LACM & $(\mathrm{CIT}) 63$ & 98357 & $\mathrm{R}$ & I. or $S$. & - & 14.7 & 16 & 12.5 & 32.1 & - & - & 25.1 \\
\hline LACM & $(\mathrm{CIT}) 63$ & 98358 & $\mathrm{R}$ & I. or S. & - & 12.6 & 14.2 & 9.8 & - & 17.35 & 16.25 & 22.7 \\
\hline LACM & (CIT) 63 & 98359 & $\mathrm{R}$ & I. or $S$. & 27.95 & 15.4 & 15.6 & 11.1 & 30.4 & 18.7 & 17.3 & 24.1 \\
\hline LACM & (CIT) 63 & 98360 & $\mathrm{R}$ & I. or $S$. & 29.2 & 15.2 & 16.5 & 11.2 & 33 & 21 & 18.9 & 25.6 \\
\hline LACM & (CIT) 63 & 98361 & $\mathrm{R}$ & I. or $S$. & 28.2 & 13.85 & 14.7 & 10.3 & 30.45 & 18.9 & 16.35 & 24.3 \\
\hline LACM & $(\mathrm{CIT}) 63$ & 98362 & $\mathrm{R}$ & I. or $S$. & 31.5 & 15.15 & 16.2 & 11.35 & 35.35 & 20.75 & 19.4 & 28.2 \\
\hline LACM & (CIT) 63 & 98363 & $\mathrm{R}$ & I. or $S$. & 25 & 11.9 & 13.15 & 9.75 & 27.75 & 16 & 15.35 & 21.5 \\
\hline LACM & (CIT) 63 & 98364 & $\mathrm{R}$ & I. or S. & 28.6 & 14.3 & 16.25 & 11.75 & 31.7 & 19.55 & 18.6 & 24.95 \\
\hline LACM & (CIT) 63 & 98365 & $\mathrm{R}$ & I. or $S$. & 26.4 & 14 & 14.8 & 8.9 & 29.65 & 18.3 & 18.5 & 23.6 \\
\hline LACM & (CIT) 63 & 98366 & $\mathrm{R}$ & I. or $S$. & 28.9 & 15.3 & 17.4 & 12.7 & 32.35 & 21.6 & 19.7 & 24.55 \\
\hline LACM & (CIT) 63 & 98367 & $\mathrm{R}$ & S. & 33.5 & 16.55 & 18.6 & 13 & 36.6 & 21.85 & 22.3 & 29 \\
\hline LACM & (CIT) 63 & 98368 & $\mathrm{R}$ & I. or $S$. & 27.1 & 13.5 & 15.15 & 9.3 & - & 18.9 & 17.25 & 32.85 \\
\hline LACM & (CIT) 63 & 98369 & $\mathrm{R}$ & I. or $S$. & 27.9 & 14.8 & 15.1 & 11.3 & 31.4 & 18.9 & 17.9 & 24 \\
\hline LACM & (CIT) 63 & 98370 & $\mathrm{R}$ & I. or $S$. & 26.55 & 12.1 & 13.85 & 10.2 & 28.45 & 16.4 & 14.85 & 22.15 \\
\hline LACM & (CIT) 63 & 98371 & $\mathrm{R}$ & I. or S. & 28.15 & 14.6 & 15.5 & 11.25 & 30.85 & 19.65 & 17.05 & 24.7 \\
\hline LACM & (CIT) 63 & 98372 & $\mathrm{R}$ & I. or $S$. & - & 13.25 & 15.7 & 11.15 & 31.65 & 18.9 & 16.65 & 24.65 \\
\hline LACM & $(\mathrm{CIT}) 63$ & 98373 & $\mathrm{R}$ & I. or $S$. & 29 & 13.75 & 15.3 & 11.1 & 31.4 & 19 & 18 & 24.45 \\
\hline
\end{tabular}




\begin{tabular}{|c|c|c|c|c|c|c|c|c|c|c|c|c|}
\hline Museum & Loc. \# & $\begin{array}{c}\text { Specimen } \\
\#\end{array}$ & Side & Taxon & LM & TD & TI & TP & LL & WD & WI & LI \\
\hline LACM & $(\mathrm{CIT}) 63$ & 98374 & $\mathrm{R}$ & I. or S. & 28.7 & 12.95 & 14.3 & 11.5 & 29.95 & 19.6 & 19.3 & 23.7 \\
\hline LACM & $(\mathrm{CIT}) 63$ & 98375 & $\mathrm{R}$ & I. or $S$. & 27.7 & 13.55 & 15.35 & 11.2 & 30.45 & 18.8 & 18.05 & 24.5 \\
\hline LACM & $(\mathrm{CIT}) 63$ & 98376 & $\mathrm{R}$ & S. & 30.75 & 16.3 & 18.05 & 13.15 & 33.75 & 21.7 & 20.45 & 27 \\
\hline LACM & $(\mathrm{CIT}) 63$ & 98377 & $\mathrm{R}$ & I. or $S$. & - & 13.85 & 15.3 & 10.9 & 31.2 & 19.5 & 18.7 & 24.25 \\
\hline LACM & (CIT) 63 & 98378 & $\mathrm{R}$ & I. or S. & - & 13.9 & 14.4 & 10.75 & 30.5 & - & 16.7 & 23.8 \\
\hline LACM & (CIT) 63 & 98379 & $\mathrm{R}$ & I. or S. & 25.1 & 12.75 & 13.35 & 9.6 & 27.1 & 16.2 & 16 & 21.1 \\
\hline LACM & $(\mathrm{CIT}) 63$ & 98380 & $\mathrm{R}$ & I. or $S$. & 27.5 & 14 & 15.7 & 11.8 & 31.15 & 18.5 & 19.4 & 23.3 \\
\hline LACM & $(\mathrm{CIT}) 63$ & 98381 & $\mathrm{R}$ & I. or S. & 28.2 & 14.45 & 14.1 & 9.9 & 30.4 & 17.5 & 15.7 & 24.45 \\
\hline LACM & (CIT) 63 & 98382 & $\mathrm{R}$ & I. or S. & 25 & 15.85 & 13.1 & 9.55 & 27.3 & 17.45 & 16.7 & 21.5 \\
\hline LACM & (CIT) 63 & 98383 & $\mathrm{R}$ & I. or $S$. & 28.5 & 14.9 & 16.2 & 11 & 30.9 & 19.25 & 19.5 & 24.4 \\
\hline LACM & $(\mathrm{CIT}) 63$ & 98384 & $\mathrm{R}$ & I. or S. & 27.9 & 14.45 & 18.75 & 11.1 & 30.75 & 19.05 & 19.05 & 24 \\
\hline LACM & $(\mathrm{CIT}) 63$ & 98385 & $\mathrm{R}$ & I. or $S$. & 27.75 & 13.6 & 15.7 & 11.35 & 31.05 & 18.8 & 17.2 & 23.95 \\
\hline LACM & $(\mathrm{CIT}) 63$ & 98386 & $\mathrm{R}$ & I. or S. & 27.95 & 14.45 & 15.1 & 10.9 & 29.9 & 18.25 & 16.8 & 23.5 \\
\hline LACM & $(\mathrm{CIT}) 63$ & 98387 & $\mathrm{R}$ & I. or $S$. & 29.1 & 13.4 & 15.35 & 10.8 & 31.8 & 19.2 & 18.2 & 24.7 \\
\hline LACM & $(\mathrm{CIT}) 63$ & 98402 & L & I. or $S$. & 29.3 & 13.95 & 15.45 & 11.75 & 32.45 & 20.35 & 19.9 & 25.5 \\
\hline LACM & (CIT) 63 & 98403 & L & I. or S. & 29.05 & 14.75 & 16.2 & 12.55 & 32.85 & 19.9 & 19.3 & 25.6 \\
\hline LACM & $(\mathrm{CIT}) 63$ & 98404 & L & I. & 23.4 & 12.45 & 12.25 & 9.6 & 25.2 & 14.7 & 14.1 & 19.55 \\
\hline LACM & (CIT) 63 & 98405 & $\mathrm{~L}$ & I. or $S$. & 25.9 & 13.15 & 14.2 & 10.15 & 29.15 & 18.6 & 17.95 & 22.95 \\
\hline LACM & (CIT) 63 & 98405 & L & I. or $S$. & - & 11.9 & 15.5 & 11.25 & 31.4 & 18.4 & 17.2 & - \\
\hline LACM & $(\mathrm{CIT}) 63$ & 98407 & L & I. or S. & 26.55 & 11.9 & 14.15 & - & - & 17.2 & 17.15 & - \\
\hline LACM & $(\mathrm{CIT}) 63$ & 98408 & $\mathrm{~L}$ & I. or $S$. & 29.2 & 14.1 & 16.4 & - & - & 18.7 & - & 25.05 \\
\hline LACM & $(\mathrm{CIT}) 63$ & 98409 & L & I. or S. & 27.9 & 13.4 & 15.45 & 10.95 & 29.75 & 18.9 & 18 & 23.3 \\
\hline LACM & (CIT) 63 & 98410 & L & I. or S. & 26.85 & 14.3 & 14.6 & 11.3 & 29.1 & 18 & 17.55 & 23.35 \\
\hline LACM & (CIT) 63 & 98411 & L & I. or $S$. & 27.5 & - & - & 9.65 & 30 & 18.25 & 17 & 23.7 \\
\hline LACM & (CIT) 63 & 98412 & $L$ & I. or $S$. & 26.2 & 12.85 & 16.9 & 11.3 & 30.1 & 18.5 & 16.85 & 22.3 \\
\hline LACM & $(\mathrm{CIT}) 63$ & 98413 & $L$ & I. or $S$. & 27.3 & 12.85 & 15.55 & 10.85 & 28.4 & 18.35 & 15.45 & 23.4 \\
\hline LACM & $(\mathrm{CIT}) 63$ & 98414 & L & I. or $S$. & 29.5 & - & - & 11.1 & - & - & 18 & 24.9 \\
\hline LACM & (CIT) 63 & 98415 & L & I. or $S$. & 30.7 & 14.25 & 16.85 & 11.45 & 33.25 & 20 & 18.45 & 26.05 \\
\hline LACM & $(\mathrm{CIT}) 63$ & 98416 & $\mathrm{~L}$ & I. & 24.5 & 10.45 & 12.05 & 7.8 & - & 13.7 & 13.7 & 21.4 \\
\hline LACM & (CIT) 63 & 98417 & $L$ & I. or S. & 28.05 & 14.8 & 15.35 & 11.7 & 30.2 & 18.6 & 17.4 & 23.65 \\
\hline LACM & (CIT) 63 & 98418 & $L$ & I. or S. & 28.75 & 13.3 & 15 & 11.4 & 29.9 & 18 & 16.8 & 23.4 \\
\hline LACM & $(\mathrm{CIT}) 63$ & 98419 & L & I. or $S$. & 25 & 12.55 & 14 & 10.1 & 17.4 & 17.35 & 16.35 & 21.5 \\
\hline LACM & $(\mathrm{CIT}) 63$ & 98420 & L & I. or S. & 28.1 & 13.3 & 14.9 & 10.6 & 30.45 & 19.05 & 18.3 & 24 \\
\hline LACM & $(\mathrm{CIT}) 63$ & 98421 & L & I. or $S$. & 26.65 & 13.6 & 14.4 & 11.5 & 29.25 & 17.9 & 17.25 & 32.15 \\
\hline LACM & $(\mathrm{CIT}) 63$ & 98422 & L & I. or S. & 28.1 & 15.8 & 16.15 & 11.85 & 31.6 & - & 18.6 & 24.65 \\
\hline LACM & $(\mathrm{CIT}) 63$ & 98423 & L & I. or $S$. & 25.8 & 13.75 & 13.35 & 9.25 & 28.85 & 16.9 & 15.85 & 22.15 \\
\hline LACM & (CIT) 63 & 98424 & L & I. or $S$. & 28.2 & 14.3 & 16.15 & 11.4 & 30.7 & 19.25 & 17.9 & 24.05 \\
\hline LACM & (CIT) 63 & 98425 & L & I. or S. & 26.35 & 13.15 & 13.9 & 9.8 & 27.7 & 17.4 & 17.85 & 22.3 \\
\hline LACM & (CIT) 63 & 98426 & $\mathrm{~L}$ & I. or S. & 26.25 & 14.3 & 15.35 & 10.65 & - & 17.65 & 16.1 & 21.45 \\
\hline LACM & $(\mathrm{CIT}) 63$ & 98427 & L & I. or S. & 28.5 & 13.6 & 14.65 & 12 & 30.8 & 18.1 & 16.9 & 24 \\
\hline LACM & (CIT) 63 & 98428 & L & I. or $S$. & 29.1 & - & 16.55 & 11.6 & 31.9 & 20 & 17.75 & 24.7 \\
\hline
\end{tabular}




\begin{tabular}{|c|c|c|c|c|c|c|c|c|c|c|c|c|}
\hline Museum & Loc.\# & $\begin{array}{c}\text { Specimen } \\
\#\end{array}$ & Side & Taxon & LM & TD & $\mathrm{TI}$ & TP & LL & WD & WI & LI \\
\hline LACM & (CIT) 63 & 98429 & L & I. or $S$. & 26.1 & 13.7 & 13.95 & 10.7 & 28.7 & 17.9 & 18.2 & 22.95 \\
\hline LACM & (CIT) 63 & 98430 & L & I. or $S$. & - & 13.9 & 15.6 & 3.3 & - & 13 & 16.2 & 23.4 \\
\hline LACM & (CIT) 63 & 98431 & L & I. or $S$. & 28.1 & 12.9 & 14.45 & 11.8 & 30.5 & 18.1 & 17.3 & 23.7 \\
\hline LACM & (CIT) 63 & 98432 & L & I. or $S$. & 30.8 & 15.7 & 16.45 & - & - & 20.4 & 19 & - \\
\hline LACM & (CIT) 63 & 98433 & L & I. or $S$. & 28.2 & 15.45 & 17.1 & 11.5 & 31.7 & 19.4 & 18.7 & 24.5 \\
\hline LACM & (CIT) 63 & 98434 & $\mathrm{~L}$ & I. or $S$. & 27.75 & 14.85 & 15.5 & 11.5 & 31.3 & 19.2 & 18.4 & 24.3 \\
\hline LACM & (CIT) 63 & 98435 & L & I. or $S$. & 27.1 & 12.25 & 14.1 & 9.7 & 30.5 & 18.1 & 16.9 & 23.1 \\
\hline LACM & (CIT) 63 & 98436 & L & I. or $S$. & 26.7 & 12.7 & 15 & 11.75 & - & 18.55 & 18.1 & 22.95 \\
\hline LACM & (CIT) 63 & 98437 & L & I. or $S$. & 27.8 & 13.6 & 16.1 & 11.2 & 30.2 & 18.3 & 17.55 & 23.4 \\
\hline LACM & (CIT) 63 & 98438 & L & I. or $S$. & 26.5 & 13.2 & 14.3 & 11.1 & 29.5 & 17.4 & 17.65 & 22.4 \\
\hline UCMP & 1097 & 164808 & L & I. or $S$. & 28 & 13.3 & 15.65 & 12.96 & 31.74 & 18.89 & 18.07 & 24.37 \\
\hline UCMP & 1097 & 164809 & $\mathrm{R}$ & I. or $S$. & 26.95 & 15.65 & 15.79 & 11.2 & 30.57 & 20.13 & 18.51 & 23.87 \\
\hline UCMP & 1100 & 70318 & $\mathrm{R}$ & I. or S. & 26.75 & 13.58 & 14.66 & 11.17 & 28.78 & 18.04 & 17.41 & 22.5 \\
\hline UCMP & 1100 & 153940 & $\mathrm{R}$ & I. or $S$. & 26.59 & 13.56 & 15.81 & 10.67 & 29.03 & 17.92 & 17.75 & 22.82 \\
\hline UCMP & 1100 & 153941 & $\mathrm{R}$ & I. or $S$. & 27.07 & 12.33 & 13.93 & 9.78 & 29.28 & 17.38 & 16.68 & 23.09 \\
\hline UCMP & 1100 & 153942 & $\mathrm{R}$ & I. or $S$. & 27.47 & 13.78 & 15.43 & 10.67 & 31.12 & 18.48 & 16.03 & 23.77 \\
\hline UCMP & 1100 & 153943 & $\mathrm{R}$ & I. or $S$. & 26.71 & 14.16 & 15.18 & 11.01 & 29.08 & 18.37 & 17.13 & 23.48 \\
\hline UCMP & 1100 & 153944 & $\mathrm{R}$ & I. or $S$. & - & 13.08 & 14.78 & 11.11 & - & - & - & 23.49 \\
\hline UCMP & 1100 & 153945 & $\mathrm{R}$ & S. & 30.57 & 15.08 & 16.9 & 11.8 & 34.16 & 21.41 & 20.7 & 26.94 \\
\hline UCMP & 1100 & 153946 & $\mathrm{R}$ & I. or $S$. & 28.4 & 12.85 & 14.62 & 11.33 & 30.7 & 18.77 & 17.6 & 24.12 \\
\hline UCMP & 1100 & 153947 & $\mathrm{R}$ & I. or $S$. & - & 14.82 & 15.08 & 12.13 & 31.57 & - & - & 24.82 \\
\hline UCMP & 1100 & 153948 & $\mathrm{R}$ & I. or $S$. & 29.02 & 12.82 & 15.67 & 11.66 & 30.75 & 19.54 & 17.93 & 24.57 \\
\hline UCMP & 1100 & 153949 & $\mathrm{R}$ & I. or $S$. & 27.66 & 15.58 & 15.77 & 10.33 & 30.24 & 18.21 & 17.72 & 23.46 \\
\hline UCMP & 1100 & 153950 & $\mathrm{R}$ & I. or $S$. & 28.32 & 14.76 & 16.06 & 11.7 & 30.55 & 19.69 & 19.11 & 24.85 \\
\hline UCMP & 1100 & 153951 & $\mathrm{R}$ & I. or $S$. & 26.47 & 13.35 & 14.47 & 11.08 & 29.02 & 18.41 & 16.02 & 23.12 \\
\hline UCMP & 1100 & 153952 & $\mathrm{R}$ & I. or $S$. & 25.55 & 13.14 & 14.75 & 10.15 & 27.37 & 17.25 & 15.91 & 21.75 \\
\hline UCMP & 1100 & 153953 & $\mathrm{R}$ & I. or $S$. & - & 14.59 & 14.88 & 11.23 & 29.99 & - & 18.77 & 23.47 \\
\hline UCMP & 1100 & 153954 & $\mathrm{R}$ & I. or $S$. & 26.12 & 12.2 & 14.62 & 10.4 & 28.34 & 17.66 & 16.55 & 22.56 \\
\hline UCMP & 1100 & 153955 & $\mathrm{R}$ & I. or $S$. & 28.47 & 14.8 & 15.75 & 11.69 & 31.63 & 19.49 & 18.75 & 24.98 \\
\hline UCMP & 1100 & 153956 & $\mathrm{R}$ & I. or $S$. & - & 14.32 & 16.15 & 11.41 & 30.59 & - & - & 23.81 \\
\hline UCMP & 1100 & 153957 & $\mathrm{R}$ & I. or $S$. & 26.18 & 11.93 & 14 & 10.92 & 28.12 & 17.28 & 16.04 & 21.99 \\
\hline UCMP & 1100 & 153958 & $\mathrm{R}$ & I. or $S$. & 29.3 & 17.12 & 15.8 & 12.16 & - & - & 18.11 & 25.53 \\
\hline UCMP & 1100 & 153959 & $\mathrm{R}$ & I. or $S$. & 27.16 & 13.25 & 14.74 & 10.05 & 29.09 & 17.43 & 16.98 & 23.18 \\
\hline UCMP & 1100 & 153960 & $\mathrm{R}$ & I. or $S$. & 28.97 & 16.24 & 17.4 & 12.14 & 33.33 & 20.63 & 20.07 & 25.42 \\
\hline UCMP & 1100 & 153961 & $\mathrm{R}$ & I. or $S$. & 29.75 & 15.63 & 17.72 & 11.87 & 32.94 & 20.33 & 19.51 & 25.73 \\
\hline UCMP & 1100 & 153962 & $\mathrm{R}$ & I. or $S$. & - & - & 14.99 & 10.78 & - & - & 16.92 & 24.98 \\
\hline UCMP & 1100 & 153963 & $\mathrm{R}$ & I. or $S$. & 30.14 & 16.45 & 17.55 & 12.32 & 33.21 & 21.31 & 19.31 & 26.09 \\
\hline UCMP & 1100 & 153964 & $\mathrm{R}$ & I. or S. & 30.14 & 18.15 & 17.65 & 12.7 & 33.61 & 21.26 & 20.86 & 26.48 \\
\hline UCMP & 1100 & 153965 & $\mathrm{R}$ & I. or $S$. & 29.64 & 15.24 & 16.7 & 11.74 & 31.7 & 21.35 & 19.95 & 25.53 \\
\hline UCMP & 1100 & 153966 & $\mathrm{R}$ & I. or $S$. & 26.48 & 13.36 & 14.57 & 10.04 & 28.73 & 17.75 & 16.07 & 22.54 \\
\hline UCMP & 1100 & 153967 & $\mathrm{R}$ & I. or S. & 26.12 & 12.35 & 13.89 & 9.57 & 28.27 & 15.96 & 14.93 & 22.81 \\
\hline
\end{tabular}




\begin{tabular}{|c|c|c|c|c|c|c|c|c|c|c|c|c|}
\hline Museum & Loc. \# & $\begin{array}{c}\text { Specimen } \\
\#\end{array}$ & Side & Taxon & LM & TD & $\mathrm{TI}$ & TP & LL & WD & WI & LI \\
\hline UCMP & 1100 & 153968 & $\mathrm{R}$ & I. or $S$. & - & 15.25 & 16.73 & 12.86 & 33.58 & 19.71 & 18.13 & 25.61 \\
\hline UCMP & 1100 & 153969 & $\mathrm{R}$ & I. or $S$. & 26.38 & 13.63 & 15.04 & 10.69 & 28.98 & 18.82 & 17.82 & 22.92 \\
\hline UCMP & 1100 & 153970 & $\mathrm{R}$ & I. or $S$. & 25.3 & 13.27 & 14.36 & 9.99 & 27.3 & 16.99 & 16.55 & 21.6 \\
\hline UCMP & 1100 & 153971 & $\mathrm{R}$ & S. & 30.86 & 16.13 & 18.07 & 12.72 & 34.91 & 22.21 & 18.99 & 26.97 \\
\hline UCMP & 1100 & 153972 & $\mathrm{R}$ & S. & 30.19 & 17.89 & 18.91 & 13.23 & 34.71 & 23.28 & 22.4 & 27.06 \\
\hline UCMP & 1100 & 153973 & $\mathrm{R}$ & I. or S. & 27.52 & 14.11 & 15.23 & - & - & 18.75 & 17.51 & - \\
\hline UCMP & 1100 & 153974 & $\mathrm{R}$ & I. or $S$. & - & 14.13 & 15.86 & 10.63 & 28.95 & - & - & 22.83 \\
\hline UCMP & 1100 & 153975 & $\mathrm{~L}$ & I. or S. & 28.89 & 14.83 & 16.68 & 12.88 & 31.59 & 19.44 & 19.17 & 25.38 \\
\hline UCMP & 1100 & 153976 & L & I. or $S$. & 26.44 & 14.16 & 15.6 & 11.77 & 29.26 & 17.92 & 19.07 & 22.78 \\
\hline UCMP & 1100 & 153977 & $\mathrm{~L}$ & I. or $S$. & 27.16 & 13.55 & 15.58 & 10.61 & 30.02 & 18.75 & 18.05 & 23.63 \\
\hline UCMP & 1100 & 153978 & L & I. or $S$. & 25.67 & 13.49 & 15.04 & 10.52 & 28.14 & 18.47 & 16.55 & 22.34 \\
\hline UCMP & 1100 & 153979 & L & I. or S. & 28.99 & 14.09 & 15.57 & 10.72 & 31.87 & 19.28 & 17.87 & 25.14 \\
\hline UCMP & 1100 & 153980 & L & I. or $S$. & 25.58 & 13.42 & 14.37 & 10.64 & 27.94 & 17.82 & 16.99 & 21.93 \\
\hline UCMP & 1100 & 153981 & L & I. or $S$. & 27.21 & 13.62 & 13.03 & 9.93 & 29.8 & 17.59 & - & 23.72 \\
\hline UCMP & 1100 & 153982 & L & I. or $S$. & 28.28 & 14.69 & 16.07 & 11.42 & 31.21 & 19.63 & 18.83 & 24.1 \\
\hline UCMP & 1100 & 153983 & L & I. or $S$. & 27.84 & 13.17 & 15.26 & 10.67 & 31.14 & 18.9 & 18.4 & 24.46 \\
\hline UCMP & 1100 & 153984 & $\mathrm{~L}$ & I. or $S$. & 27.87 & 14.23 & 15.53 & 10.78 & 30.6 & 19.36 & 19.56 & 24.66 \\
\hline UCMP & 1100 & 153985 & L & I. or S. & 27.68 & 13.33 & 13.31 & 11.15 & 30.17 & 18.01 & 17.46 & 23.67 \\
\hline UCMP & 1100 & 153986 & L & I. or S. & 28.17 & 13.9 & 14.42 & 10.16 & 29.05 & 18.72 & 16.33 & 24.05 \\
\hline UCMP & 1100 & 153987 & L & I. or S. & 28.08 & 14.21 & 15.93 & 11.75 & 30.99 & 19.16 & 18.1 & 24.04 \\
\hline UCMP & 1100 & 153988 & L & I. or $S$. & 28.14 & 14.35 & 15.87 & 11.5 & 30.25 & 18.73 & 18.22 & 24.55 \\
\hline UCMP & 1100 & 153989 & L & I. or $S$. & 30.32 & 16.34 & 16.61 & 11.84 & 33.47 & 20.35 & 19.39 & 25.92 \\
\hline UCMP & 1100 & 153990 & L & I. or S. & 27.23 & 14.83 & 15.46 & 11.95 & 30.51 & 19.52 & 18.73 & 23.54 \\
\hline UCMP & 1100 & 153991 & L & I. or $S$. & 25.75 & 12.57 & 14.45 & 10.23 & 27.96 & 16.96 & 16.72 & 22.06 \\
\hline UCMP & 1100 & 153992 & L & $\mathrm{I}$. & 22.18 & 8.26 & 10.33 & 9.24 & 22.76 & 15.34 & 14.62 & 19.5 \\
\hline UCMP & 1100 & 153993 & L & I. or $S$. & 27.64 & 14.82 & 15.78 & 11.47 & 30.96 & 19.7 & 17.96 & 24.14 \\
\hline UCMP & 1100 & 153994 & $\mathrm{~L}$ & I. or $S$. & 26.81 & 13.7 & 14.6 & 11.51 & 29.3 & 18.27 & 16.91 & 23.2 \\
\hline UCMP & 1100 & 153995 & L & I. or $S$. & 25.6 & 12.71 & 14.39 & 10.26 & 27.44 & 16.86 & 15.8 & 21.46 \\
\hline UCMP & 1100 & 153996 & L & I. or $S$. & 27.99 & 14.34 & 15.75 & 11.79 & 30.56 & 19.35 & 18.81 & 24.5 \\
\hline UCMP & 1100 & 153997 & L & I. or $S$. & 25.85 & 12.44 & 13.13 & 9.95 & 27.44 & 17.06 & 15.65 & 22.12 \\
\hline UCMP & 1100 & 153998 & L & I. or $S$. & - & 17.21 & 17.14 & 13.02 & 31.37 & - & - & - \\
\hline UCMP & V6570 & 35624 & L & I. or $S$. & 26.15 & 13.63 & 15.03 & 11.16 & 28.84 & 18.39 & 17.37 & 22.85 \\
\hline UCMP & V6570 & 164814 & L & I. or $S$. & 27.96 & 13.46 & 13.81 & 9.27 & 30.88 & 19.7 & 18.22 & 24.65 \\
\hline UCMP & V6570 & 164815 & L & I. or $S$. & 30.49 & 15.56 & 15.62 & 12.89 & 32.63 & 21.06 & 20.22 & 26.15 \\
\hline UCMP & V6570 & 164816 & L & I. or $S$. & 29.43 & 15.97 & 17.47 & 12.67 & 32.3 & 20.41 & 19.27 & 25.29 \\
\hline UCMP & V6570 & 164817 & L & I. or $S$. & 28.87 & 15.33 & 15.94 & 11.09 & 31.07 & 19.23 & 18.87 & 24.82 \\
\hline UCMP & V6570 & 164818 & L & I. or $S$. & 27.24 & 13.88 & 15.31 & 10.93 & 29.71 & 19.1 & 18.02 & 23.76 \\
\hline UCMP & V6570 & 164819 & L & I. or $S$. & 24.29 & 13.02 & 13.5 & 10.44 & 27.03 & 17.56 & 17.02 & 20.99 \\
\hline UCMP & V6570 & 164820 & $\mathrm{R}$ & I. or $S$. & 28.71 & 14.46 & 15.34 & 10.98 & 30.98 & 19.41 & 18.66 & 24.69 \\
\hline UCMP & V6570 & 164821 & $\mathrm{R}$ & I. or S. & 25.84 & 13.87 & 15.93 & 11.16 & - & 18.25 & 18.46 & 23.65 \\
\hline UCMP & V6570 & 164822 & $\mathrm{R}$ & I. or $S$. & 30.48 & 15.74 & 17.77 & 11.48 & 33.18 & 20.97 & 19.73 & 23.87 \\
\hline
\end{tabular}




\begin{tabular}{|c|c|c|c|c|c|c|c|c|c|c|c|c|}
\hline Museum & Loc. \# & $\begin{array}{c}\text { Specimen } \\
\#\end{array}$ & Side & Taxon & LM & TD & TI & TP & LL & WD & WI & LI \\
\hline UCMP & V6570 & 164823 & $\mathrm{R}$ & I. or $S$. & 29.12 & 13.47 & 14.69 & 11.73 & 28.91 & 16.24 & 15.91 & 25.22 \\
\hline UCMP & V6570 & 164824 & $\mathrm{R}$ & I. or $S$. & 27.41 & 14.17 & 14.82 & 11.46 & 30.27 & 18.88 & 17.3 & 24.81 \\
\hline UCMP & V6570 & 164825 & $\mathrm{R}$ & I. or $S$. & 28.41 & 14.25 & 16.83 & 11.16 & 30.82 & 19.27 & 18.15 & 23.89 \\
\hline UCMP & V6570 & 164826 & $\mathrm{R}$ & I. or $S$. & 28.7 & 14.77 & 15.63 & 11.1 & 31.28 & 18.88 & 17.99 & 24.8 \\
\hline UCMP & V6570 & 164827 & $\mathrm{R}$ & I. or $S$. & 29.32 & 14.89 & 15.92 & 11.52 & 32.53 & 21.82 & 20.86 & 25.85 \\
\hline UCMP & V6570 & 164828 & $\mathrm{R}$ & I. or S. & 27.39 & 13.09 & 14.25 & 10.78 & 29.97 & 18.49 & 15.84 & 23.27 \\
\hline UCMP & V6570 & 164829 & $\mathrm{R}$ & I. or $S$. & 29.86 & 13.67 & 16.89 & 11.57 & 31.92 & 18.73 & 18.92 & 25.35 \\
\hline UCMP & V78061 & 164810 & $\mathrm{R}$ & I. or $S$. & 26.81 & - & 14.65 & 10.87 & 29.95 & 16.83 & - & 22.24 \\
\hline UCMP & V78061 & 164811 & $\mathrm{R}$ & I. or $S$. & - & 12.89 & 14.38 & 10.42 & 29.19 & - & 15.33 & 23.34 \\
\hline UCMP & V78061 & 164812 & $\mathrm{R}$ & I. or $S$. & 28.5 & 14.19 & 15.26 & 9.86 & 30.97 & 17.64 & 17.59 & 23.81 \\
\hline UCMP & V78062 & 164813 & L & I. or S. & 25.01 & 13.8 & 13.94 & 10.89 & 26.75 & 16.09 & 15.19 & 20.71 \\
\hline UCMP & V78065 & 164751 & L & I. or $S$. & 29.72 & 15.75 & 16.87 & 12.38 & 33.74 & 18.37 & 18.72 & 25.52 \\
\hline UCMP & V78065 & 164752 & $\mathrm{R}$ & I. & 24.92 & 10.92 & 12.99 & - & 27.86 & 15.06 & 14.32 & 22.07 \\
\hline UCMP & V78069 & 164760 & $\mathrm{R}$ & I. or $S$. & 26.32 & 13.38 & 15.37 & 11.15 & 30.16 & 19.02 & - & 23.36 \\
\hline UCMP & V78069 & 164761 & L & I. or $S$. & - & 11.69 & 13.28 & 9.54 & 27.42 & 16.29 & 14.15 & 22.58 \\
\hline UCMP & V78069 & 164762 & $\mathrm{R}$ & I. or $S$. & 27.23 & 14.59 & 15.07 & 9.12 & 29.95 & 18.77 & 16.98 & 23.21 \\
\hline UCMP & V91087 & 164757 & $\mathrm{R}$ & I. or $S$. & 27.76 & 14.44 & 15.09 & 11.19 & 30.2 & 19.27 & 18.15 & 23.3 \\
\hline UCMP & V91087 & 164758 & L & I. or $S$. & 26.58 & 13.55 & 14.88 & 10.69 & 28.54 & 18.52 & 17.36 & 22.56 \\
\hline UCMP & V91087 & 164759 & $\mathrm{R}$ & I. or $S$. & - & - & - & 12.39 & - & - & 18.83 & - \\
\hline UCMP & V91089 & 164747 & L & I. & 23.12 & 11.93 & 11.75 & 9.17 & 25.03 & 13.01 & 13.87 & 19.55 \\
\hline UCMP & V91089 & 164748 & L & I. or $S$. & 25.32 & 14.05 & 13.5 & 11.03 & 27.97 & 17.1 & 17.05 & 22.18 \\
\hline UCMP & V91089 & 164749 & L & I. or $S$. & 28.49 & - & - & - & - & - & - & 24.03 \\
\hline UCMP & V91089 & 164750 & $\mathrm{R}$ & I. or $S$. & 27.69 & 13.88 & 15.33 & 10.21 & 29.01 & 17.3 & 15.82 & 23.52 \\
\hline UCMP & V91089 & 164763 & L & I. or $S$. & 28.28 & 14.59 & 16.32 & 12.11 & 32.12 & 18.44 & 16.61 & 24.49 \\
\hline UCMP & V91089 & 164764 & $\mathrm{R}$ & I. or S. & 30.13 & 15.39 & 16.6 & 12.27 & 32.95 & 21.18 & 19.13 & 26.09 \\
\hline UCMP & V91089 & 164765 & $\mathrm{R}$ & I. or $S$. & 25.66 & 12.84 & 13.66 & 9.65 & 27.56 & 16 & 14.89 & 21.81 \\
\hline UCMP & V91095 & 164775 & $\mathrm{R}$ & I. or $S$. & 30.4 & 15.92 & 17.53 & 13.8 & 33.67 & 19.85 & 18.56 & 26.37 \\
\hline UCMP & V91095 & 164776 & L & I. or $S$. & 27.9 & 14.1 & 15.16 & 11.04 & 30.13 & 19.45 & 19.84 & 23.76 \\
\hline UCMP & V91095 & 164793 & L & I. or S. & 26.92 & 12.91 & 14.33 & 11.23 & 29.8 & 18.34 & 17.18 & 22.95 \\
\hline UCMP & V91095 & 164794 & $\mathrm{R}$ & I. or $S$. & 27.85 & 15.89 & 16.51 & 12.11 & 30.64 & 19.41 & 20.12 & 24.23 \\
\hline UCMP & V91095 & 164795 & $\mathrm{R}$ & I. or $S$. & 26.85 & 15.32 & 15.28 & 10.1 & 29.73 & 19.06 & 17.61 & 23.25 \\
\hline UCMP & V91095 & 164796 & $\mathrm{R}$ & I. or S. & 25.87 & 14.67 & 14.6 & 10.82 & 29.41 & 18.75 & 18.13 & 22.47 \\
\hline UCMP & V91096 & 164787 & L & I. or $S$. & 28.49 & 13.62 & 15.17 & 11.4 & 30.52 & 18.88 & 19.22 & 24.23 \\
\hline UCMP & V91096 & 164788 & L & I. or S. & 27.37 & 13.5 & 15.21 & 11.37 & 30.55 & 17.95 & 16.06 & 22.8 \\
\hline UCMP & V91096 & 164797 & L & I. or $S$. & 28.37 & 15.45 & 15.61 & 11.96 & 30.07 & 18.43 & 17.57 & 23.94 \\
\hline UCMP & V91097 & 153999 & $\mathrm{R}$ & I. or $S$. & 30.36 & 13.58 & 16.31 & 12.06 & 33.7 & 21.26 & 21.52 & 26.1 \\
\hline UCMP & V91097 & 164767 & $\mathrm{R}$ & I. or S. & 30.3 & - & - & - & - & - & - & 26.04 \\
\hline UCMP & V91097 & 164768 & L & S. & 31.96 & 15.29 & 18 & 12.49 & 36.13 & 22.11 & 21.1 & 27.58 \\
\hline UCMP & V91097 & 164769 & L & I. or $S$. & 29.18 & 15.2 & 16.01 & 11.95 & 31.54 & 19.56 & 19.61 & 25.76 \\
\hline UCMP & V91097 & 164770 & $\mathrm{R}$ & I. or S. & - & 16.49 & 16.21 & 11.6 & 32.42 & 19.7 & 17.55 & 26.6 \\
\hline UCMP & V91097 & 164777 & $\mathrm{R}$ & I. or $S$. & 30.45 & - & - & - & - & - & - & 26.78 \\
\hline
\end{tabular}




\begin{tabular}{|c|c|c|c|c|c|c|c|c|c|c|c|c|}
\hline Museum & Loc. \# & $\begin{array}{c}\text { Specimen } \\
\#\end{array}$ & Side & Taxon & LM & TD & TI & TP & LL & WD & WI & LI \\
\hline UCMP & V91097 & 164778 & $L$ & I. or S. & 29.8 & 16.33 & 16.81 & 11.91 & 32.9 & 19.66 & 20.06 & 25.19 \\
\hline UCMP & V91097 & 164779 & L & I. or $S$. & 29.25 & 15.96 & 17.13 & 12.28 & 32.12 & 20.2 & 19.07 & 25.23 \\
\hline UCMP & V91097 & 164780 & L & I. or $S$. & 28.08 & 15.5 & 15.74 & 11.73 & 30.88 & 18.76 & 19.36 & 23.95 \\
\hline UCMP & V91097 & 164782 & $\mathrm{R}$ & I. or S. & 29.84 & 14.6 & 16.13 & 10.39 & - & 19.37 & 17.07 & 24.62 \\
\hline UCMP & V91097 & 164783 & $\mathrm{R}$ & I. or $S$. & 28.84 & 13.37 & 14.97 & 10.96 & 30.28 & 19.85 & 19.02 & 24.95 \\
\hline UCMP & V91097 & 164784 & $\mathrm{R}$ & I. or S. & 30.46 & 16.99 & 17.11 & - & - & 20.4 & 19.81 & 26.56 \\
\hline UCMP & V91097 & 164785 & $\mathrm{R}$ & I. or S. & - & 13.9 & 14.8 & 10.11 & 29.26 & 17.91 & 16.34 & 22.75 \\
\hline UCMP & V91097 & 164790 & L & I. or $S$. & 27.1 & 13.42 & 15.1 & 11.25 & 29.26 & 17.24 & 16.92 & 23.3 \\
\hline UCMP & V91097 & 164791 & L & S. & 30.43 & 16.86 & 17.71 & 13.67 & 34.79 & 21.56 & 20.56 & 26.48 \\
\hline UCMP & V91097 & 164792 & $\mathrm{R}$ & I. or $S$. & - & 15.65 & 16.29 & 12.21 & 34.7 & - & 18.22 & 26.84 \\
\hline UCMP & V91097 & 164799 & $\mathrm{R}$ & I. or $S$. & - & 14.56 & 14.6 & 10.35 & 28.85 & - & - & 22.98 \\
\hline UCMP & V91097 & 164800 & L & I. or S. & - & 15.75 & 16.07 & 11.1 & 30.67 & - & 16.02 & - \\
\hline UCMP & V91097 & 164801 & L & I. or $S$. & 28.36 & 15.26 & 16.05 & 11.16 & 31.91 & 19.88 & 20.16 & 24.94 \\
\hline UCMP & V91097 & 164804 & $\mathrm{R}$ & I. or $S$. & 28.66 & 14.38 & 14.92 & 11.84 & 32.16 & - & 17.77 & 24.46 \\
\hline UCMP & V91097 & 164806 & $\mathrm{R}$ & I. or $S$. & 28.05 & 15 & 15.28 & 10.73 & 31.49 & 17.74 & 18.14 & 23.63 \\
\hline UCMP & V91097 & 164807 & L & I. or $S$. & - & 14.76 & 16.13 & 11.26 & 32.41 & - & 17.67 & 24.99 \\
\hline UCMP & V99408 & 158341 & $\mathrm{R}$ & I. or S. & 28.94 & 15.35 & 15.9 & 11.98 & 32.74 & 19.91 & 17.71 & 25.13 \\
\hline UCMP & V99412 & 158394 & $\mathrm{R}$ & I. or $S$. & - & 13.86 & 13.74 & 9.69 & - & 15.96 & 13.34 & 20.62 \\
\hline UCMP & V99414 & 157152 & $\mathrm{R}$ & I. & 24.87 & 12.83 & 12.6 & 8.16 & 26.05 & 14.95 & 14.06 & 21.04 \\
\hline UCMP & V99414 & 157171 & L & I. or $S$. & - & 13.23 & 13.82 & 10.2 & 27.5 & - & - & 21.19 \\
\hline UCMP & V99416 & 157221 & L & I. or $S$. & - & 15.51 & 17.32 & 11.74 & 33.93 & - & - & 25.6 \\
\hline UCMP & V99443 & 157243 & $\mathrm{R}$ & I. or $S$. & 29.13 & 15.21 & 16.57 & 11.89 & 31.78 & 18.94 & 17.25 & 25.16 \\
\hline UCMP & V99443 & 157249 & $\mathrm{~L}$ & I. or S. & - & 13.48 & 13.98 & 9.91 & 29.78 & - & - & - \\
\hline
\end{tabular}




\section{APPENDIX 2}

Results of the discriminant function analysis on the set of measurements of Antilocapra americana. Abbreviations: M, male; F, female; R, right; L, left. All specimens are from the museum of Vertebrate Zoology (MVZ).

\begin{tabular}{|c|c|c|c|c|c|c|c|c|}
\hline $\begin{array}{l}\text { Specimen } \\
\text { number }\end{array}$ & $M / F$ & Side & $\begin{array}{l}\text { Predicted Body Mass } \\
\text { (Kg) }\end{array}$ & $\begin{array}{l}\text { Predicted } \\
\text { Habitat }\end{array}$ & $\begin{array}{c}\text { Forest } \\
\%\end{array}$ & $\begin{array}{c}\text { Heavy cover } \\
\%\end{array}$ & $\begin{array}{c}\text { Light cover } \\
\%\end{array}$ & $\begin{array}{c}\text { Open } \\
\%\end{array}$ \\
\hline 8299 & $M$ & $\mathrm{R}$ & 55.496 & $\mathrm{O}$ & 0.004 & 0.035 & 0.267 & 0.694 \\
\hline 8299 & $M$ & L & 40.981 & $\mathrm{~F}$ & 0.557 & 0.022 & 0.148 & 0.273 \\
\hline 19231 & $\mathrm{M}$ & $\mathrm{R}$ & 40.530 & O & 0.176 & 0.034 & 0.192 & 0.599 \\
\hline 19231 & $\mathrm{M}$ & $\mathrm{L}$ & n.a. & $\mathrm{H}$ & 0.000 & 1.000 & 0.000 & 0.000 \\
\hline 31157 & $F$ & $\mathrm{R}$ & n.a. & n.a. & n.a. & n.a. & n.a. & n.a. \\
\hline 31157 & $F$ & $\mathrm{~L}$ & 54.255 & L & 0.037 & 0.065 & 0.578 & 0.320 \\
\hline 38313 & $?$ & $\mathrm{R}$ & 56.090 & L & 0.031 & 0.090 & 0.551 & 0.328 \\
\hline 38313 & $?$ & L & 53.177 & L & 0.122 & 0.195 & 0.493 & 0.190 \\
\hline 40146 & $?$ & $\mathrm{R}$ & 54.760 & L & 0.084 & 0.237 & 0.531 & 0.149 \\
\hline 40146 & $?$ & $L$ & 47.778 & $\mathrm{~L}$ & 0.053 & 0.047 & 0.635 & 0.265 \\
\hline 40147 & $?$ & $\mathrm{R}$ & 49.618 & $\mathrm{~L}$ & 0.016 & 0.101 & 0.470 & 0.413 \\
\hline 40147 & $?$ & $\mathrm{~L}$ & 44.384 & L & 0.048 & 0.049 & 0.729 & 0.175 \\
\hline 44387 & $\mathrm{M}$ & $\mathrm{R}$ & 44.858 & L & 0.083 & 0.035 & 0.742 & 0.141 \\
\hline 44387 & $\mathrm{M}$ & L & 56.509 & 0 & 0.012 & 0.043 & 0.341 & 0.604 \\
\hline 78223 & $\mathrm{M}$ & $\mathrm{R}$ & 57.305 & $\mathrm{O}$ & 0.051 & 0.025 & 0.236 & 0.687 \\
\hline 78223 & $\mathrm{M}$ & L & 56.014 & L & 0.018 & 0.126 & 0.691 & 0.166 \\
\hline 88135 & $\mathrm{~F}$ & $L$ & 57.515 & L & 0.028 & 0.072 & 0.637 & 0.264 \\
\hline 98090 & $\mathrm{M}$ & $\mathrm{R}$ & 53.817 & $\mathrm{~L}$ & 0.066 & 0.098 & 0.587 & 0.249 \\
\hline 98090 & $\mathrm{M}$ & $L$ & 55.764 & $\mathrm{~L}$ & 0.029 & 0.045 & 0.745 & 0.181 \\
\hline 181287 & $?$ & $\mathrm{R}$ & 59.372 & $\mathrm{O}$ & 0.029 & 0.049 & 0.295 & 0.627 \\
\hline 184200 & $F$ & $\mathrm{R}$ & 61.397 & $\mathrm{O}$ & 0.022 & 0.033 & 0.249 & 0.697 \\
\hline 184200 & $\mathrm{~F}$ & L & 56.011 & $\mathrm{~L}$ & 0.036 & 0.185 & 0.492 & 0.287 \\
\hline 184202 & $?$ & $\mathrm{R}$ & 55.838 & $\mathrm{O}$ & 0.028 & 0.235 & 0.347 & 0.391 \\
\hline 184202 & $?$ & $\mathrm{~L}$ & 41.912 & $\mathrm{~L}$ & 0.081 & 0.092 & 0.675 & 0.151 \\
\hline 186277 & $F$ & $\mathrm{R}$ & 58.141 & L & 0.011 & 0.052 & 0.495 & 0.442 \\
\hline 186277 & $\mathrm{~F}$ & $\mathrm{~L}$ & 56.248 & $\mathrm{O}$ & 0.024 & 0.035 & 0.424 & 0.518 \\
\hline
\end{tabular}

